\title{
Does Emancipation Matter? Fertility of Chinese International Migrants to the United States and Nonmigrants during China's One-child Policy Period
}

\author{
Wanli Nie ${ }^{1}$ and Pau Baizan ${ }^{2}$ \\ ${ }^{1}$ Université catholique de Louvain, Belgium \\ ${ }^{2}$ Universitat Pompeu Fabra and Institució Catalana de Recerca i Estudis Avançats \\ (ICREA), Barcelona, Spain
}

\begin{abstract}
This article investigates the impact of international migration to the United States on the level and timing of Chinese migrants' fertility. We compare Chinese women who did not leave the country (nonmigrants) and were subject to restrictive family policies from 1974 to 2015 to those who moved to the United States (migrants) and were, thus, “emancipated" from these policies. We theoretically develop and empirically test the emancipation hypothesis that migrants should have a higher fertility than nonmigrants, as well as an earlier timing of childbearing. This emancipation effect is hypothesized to decline across birth cohorts. We use data from the 2000 US census, the 2005 American Community Survey, the 2000 Chinese census, and the 2005 Chinese 1\% Population Survey and discrete-time event history models to analyze first, second and third births, and migration as joint processes, to account for selection effects. The results show that Chinese migrants to the United States had substantially higher childbearing probabilities after migration, compared with non-migrants in China, especially for
\end{abstract}


second and third births. Moreover, our analyses indicate that the migration process is selective of migrants with lower fertility. Overall, the results show how international migration from China to the United States can lead to an increase in migrant women's fertility, accounting for disruption, adaptation, and selection effects. The rapidly increased fertility after migration from China to the United States might have implications on other migration contexts where fertility at the origin country is dropping rapidly while that in the destination country is relatively stable.

Keywords: fertility, international migration, one-child policy, China, emancipation effect. 


\section{Introduction}

This article investigates the impact of international migration to the United States on Chinese migrants' fertility by comparing them with non-migrants living in China. We focus on the effect of being free from China's family policy. Hwang and Saenz (1997) describe this freedom as the "emancipation" effect, which means that the "fertility of Chinese women, which was kept low by the Chinese fertility policies, should bounce back after emigration to the United States" (p.50). Indeed, China's family policy allowed for only one child in most cases from 1980 to $2015 .{ }^{1}$ Having more children than allowed led to a substantial financial penalty for Chinese families, equivalent to several times the annual household income for each child exceeding the quota ${ }^{2}$ (The State Council Order No. 357, Administrative Measures for the Collection of Social Support, 2002). International migration's effects on the timing and level of fertility are obviously not limited to the possible emancipation effect or being free from China's family policies. Several other processes linked to international migration including the possible migrant selection effect in terms of (unmeasured) characteristics leading to a particular fertility behavior, the disruption caused by migration, and the adaptation of fertility to the new environment after migration - are likely to be intertwined with the emancipation effect and, therefore, require close examination (Adserà and Ferrer 2016; Kulu 2005).

Fertility levels in China and the United States showed different trends. China saw its period total fertility rate (TFR) drop dramatically from more than six children during the 1960 s per woman to

\footnotetext{
${ }^{1}$ On September 25th, 1979, the Chinese government published "An open letter to all Communists and Communist Youth League members on the issue of controlling population growth in our country" (Chinese Communist Party Central Committee, 1979), which marked the starting point of the "one-child policy." Under some circumstances, two children were allowed. See Table 1 in the Online Appendix for more details on the family policy. ${ }^{2}$ The penalty for each extra child beyond the policy's quota varied by province but was generally expensive for many households.
} 
approximately 1.66 children per woman by 2015 (World Bank, 2015³). While the United States has no restrictive birth control policy, ${ }^{4}$ its TFR decreased slightly from 1960 to 1975 but bounced back and has since stabilized at approximately two children per woman (The World Bank data, 1960-2019). ${ }^{5}$ The two countries' period TFR levels intersected during the mid-1990s (see Figure 1). The drivers of fertility decline in China have been hotly debated (e.g., Gu, Wang, Guo \& Zhang, 2007; Cai 2010). Some have argued that the one-child policy "remains a core element" in China's family policies and explains fertility trends (Gu, Wang, Guo, \& Zhang 2007). Others view China's below-replacement fertility level as "to a great extent" driven by social and economic development (Cai 2010) or a fundamental shift in fertility intentions: in Jiangsu Province, among females eligible to have two children, many have had only one (Zheng et al. 2009).

This article shows that Chinese migrants to the United States are disproportionally drawn from some groups of the Chinese population holding some (unobserved) characteristics that lead to a lower fertility than Chinese non-migrants. Controlling for such selection is crucial for assessing the effects of emancipation from Chinese policies and for a non-biased estimation of the disruption and adaptation effects. Consistent with Hwang and Saenz (1997), this article finds that migration to the United States led to an acceleration of first-birth timing after migration and a sharp increase in the second- and, to a lesser extent, third-birth probabilities. Second births, we show, are the most affected by China's onechild policy, and the dramatic increase in their probabilities after migration implies a convergence for

\footnotetext{
3 TFR of China from 1960 to 2018 available at https://data.worldbank.org/indicator/SP.DYN.TFRT.IN?locations=CN

${ }^{4}$ In 1965, the US Supreme Court granted heterosexual married couples the right to use birth control. This amendment to the law was aimed to protect the "right to privacy." For further details, see Griswold v. Connecticut, 381 U.S. 479.

5 TFR levels differ substantially according to the source. The levels provided in this article reflect consensus among researchers (Gietel-Basten 2019). Here, we cite data from the World Bank, which are available at https://datacommons.org/tools/timeline\#\&place=country/USA\&statsVar=FertilityRate_Person_Female
} 
migrants' fertility with that of the United States. Moreover, we demonstrate that this emancipation effect decreases across birth cohorts (i.e., for women born from the 1960s to the 1980s), consistently with the underlying downward fertility trend in China and a weaker role of China's family policies on fertility levels attained. This article also shows that son preference is altered by migration. If a woman's previous births were all females, those who were migrants were less likely to continue giving birth than were non-migrants, showing adaptation to a society with a weaker preference for sons.

This article's contribution to studies on migrant's fertility is threefold. First, it analyzes the emancipation hypothesis, using recent data that reflect major changes that have occurred to both internal and international migration in China (Liang and Miao 2013), and, thus, updates and adds to earlier work (e.g., Hwang and Saenz (1997)). Second, this article examines the emancipation hypothesis more directly than previous scholarship (e.g., Hwang and Saenz (1997)) by comparing the fertility of Chinese females subject to China's family policy (according to time and province) with the fertility of Chinese female migrants living in the United States and, thus, free from China's family policies. By doing so, we provide relevant insights on the impact of both family policies and migration on fertility. Third, contrary to migration systems that involve migrants moving from a country of higher fertility to a country of lower fertility, this article studies migration from a country of lower fertility to a country of higher fertility (Figure 1). As fertility levels fall dramatically in many developing regions while fertility levels in some of the richest countries are close to replacement level (Myrskylä, Kohler, and Billari 2009), migrating from a country of lower fertility to one of higher fertility might become more common in the future.

To expand upon these ideas, the remainder of the article is structured as follows. Section 2 discusses the theoretical foundations of the emancipation hypothesis and other hypotheses relevant to 
explaining migrant fertility behavior. Sections 3 and 4 briefly explain the evolution of China's family policies since the mid-1960s and of Chinese migration to the United States, respectively. Section 5 describes our data and methods. Section 6 and 7 present and discuss our results, respectively.

\section{Theoretical framework and hypotheses}

\subsection{The emancipation hypothesis}

From 1980 to 2015, the Chinese government implemented a one-child policy to decrease the national fertility level by imposing a gradient of limitation on the first, second, third, and higher-order births ( $\mathrm{Gu}$ et al. 2007). Analysts have confirmed that the one-child policy influenced the timing and level of fertility in China, although the extent of the effects is somewhat disputed (Bongaarts and Greenhalgh 1985; Cai 2010; Feeney and Feng 1993; Goodkind 2017). China's one-child policy allowed for the first birth; however, the "later-longer-fewer" ${ }^{6}$ policy, started in 1974, promoted delayed marriage, which affected first births' timing in a context where almost all births occurred within marital unions (Bongaarts and Greenhalgh 1985). Notably, within the one-child policy framework, second births were sometimes allowed (Gu et al. 2007) (see Appendix Table A1). This privilege was contingent upon many factors, such as the province in which the mother resided and whether she had an agricultural hukou (i.e., a rural household registration), as is discussed below. The third birth was almost never permitted after 1980, with few exceptions (i.e., female herders in Tibet could give birth to at most three children) (Gu et al. 2007).

\footnotetext{
6 The "later-longer-fewer" policy's main features (later marriage, longer birth intervals, and fewer children) continued to hold even after a comprehensive two-child policy was enacted (Law of the People's Republic of China on Population and Family Planning (2015 Amendment, effective at the time of drafting this article)).
} 
Additionally, within-country differentials in the policies could lead to an emancipation effect (Yang 2000). The literature on internal migration's effect on fertility in China, however, has reached mixed conclusions on the emancipation hypothesis. Yang (2000), for example, argued that rural-tourban temporary migrants who were registered as rural dwellers but lived in urban areas circumvented the one-child-per-family policy because fertility policies were stricter for urban residents than rural residents. Liang et al. (2014), though, showed that rural-to-urban migrants' fertility decreased while that of urban-to-rural migrants increased. Goldstein et al. (1997) demonstrated that temporary internal migrants' fertility did not significantly differ from that of non-migrants in China's Hubei province.

By contrast, there has been less research on the emancipation hypothesis applied to Chinese international migration. An exception is Hwang and Saenz (1997), who used the 1990 US census to demonstrate that Chinese females who migrated to the United States from mainland China had a higher fertility level than those who migrated from other East Asian societies without fertility restrictions (mostly Taiwan, Hong Kong, and Vietnam). This higher fertility outcome was attributed to an "emancipation" effect, meaning that fertility should increase once policy restraints are released (i.e., after migrating to the United States). However, Hwang and Saenz (1997) did not compare Chinese international migrants' fertility with that of Chinese non-migrants living in mainland China, as we do here. Furthermore, they employed cross-sectional data and methods, which limit the reliability of their results.

Overall, then, the emancipation hypothesis has not been properly examined in the context of Chinese international migration. In its original form, this hypothesis suggests that migrants' fertility levels should increase once they leave China and are free from its family policies (Hwang and Saenz, 1997). However, a more precise and nuanced formulation is necessary on theoretical grounds and must 
be empirically investigated. In this article, we study the following aspects of the emancipation effect. First, as fertility policies have different effects on each birth order, the emancipation effect should differ between them as well, especially for second births, which were the policy's main target. Therefore, we expect that if the emancipation hypothesis holds, Chinese migrants in the United States should have a higher fertility level than Chinese non-migrants subject to policy restrictions on second and third births, while first births probabilities should be less affected by migration (Hypothesis 1).

Second, the family policies implemented in China led to an increase in the age of childbearing. This postponement was achieved mainly as a result of establishing a higher minimum age at marriage, which led to a postponement of first births (Feeney and Wang 1993; Wang 2015). In this case, emancipation from China's family policies through migration should involve an earlier timing of childbearing, as individuals were no longer subject to restrictions in the age at marriage. This earlier timing at childbearing should mainly affect first birth, while second and third births should be less affected, once we control for age at first birth. Therefore, we expect that once in the United States, Chinese migrants should have an earlier timing of fertility (Hypothesis2).

Third, although the effects of China's family policies on actual fertility levels are controversial (Goodkind 2017; Zhao and Zhang 2018), there is more agreement that these effects are likely to decline over time (Cai 2010; Gu et al. 2007). China's rapid socioeconomic change during the period examined in this article resulted in fewer females having second or third births (childlessness has increased only moderately (Djundeva, Dykstra, and Emery 2019)). China's economic development involved a decline with respect to pre-existing fertility preferences and levels, independently or in interaction with the family policies (Cai 2010). Notably, the one-child policy's effect on China's TFR by the end of 2015, when the policy was ended, was small (Gietel-Basten 2019). If, then, the policies' effect declined over 
time, the same should apply to the emancipation effect. Therefore, assuming a declining gap between fertility preferences in the Chinese population and the fertility level imposed by China's extant policies, we should observe a decreasing emancipation effect across birth cohorts. As a result, migration's positive effect on fertility should decline across birth cohorts (Hypothesis 3).

\subsection{Migration adaptation hypothesis}

The adaptation hypothesis holds that migrant fertility should converge toward that of natives in less than 10 years (Milewski 2010) because migrants and natives are subject to similar socioeconomic conditions (Chattopadhyay, White, and Debpuur 2006). At least two factors, however, affect the possibly incomplete convergence of Chinese migrants' fertility levels with those of the US native-born population. One factor is Chinese people's spatial segregation in the United States: a substantial portion of the Chinese population form ethnic communities that symbolize and sustain their ethnic identity and inhibit cultural integration, including English language learning (Logan, Zhang, and Alba 2002). The other factor is Chinese Americans' complex socioeconomic situation. Chinese immigrants in the United States have, on average, higher educational and occupational attainment compared to the overall foreign- and native-born populations (Echeverria-Estrada and Batalova 2020). Yet they are also highly polarized, with one group highly educated and acculturated to American society and the other group poorly educated and maintaining much of the traditional ethnic culture (Wong 1995; Zhou and Xiong 2005).

Furthermore, as mentioned above, fertility preferences have changed among the population living in China since the 1970s, dropping below replacement fertility since the early 2000s (Basten and Gu 2013; Cai 2010). Thus, irrespective of China's family policies, for an increasingly larger proportion of 
Chinese female migrants, adapting to US society is likely to involve an increase in their fertility, especially in the probability of bearing a second birth. Migration's impact, though, is more ambiguous for third births. Older birth cohorts had a third birth more often than younger birth cohorts, and in such a case, adaptation after migration may have involved a reduction in these females' probability of bearing a third birth. Additionally, for more recent birth cohorts, adaptation to US society, if anything, may have involved some increase in third birth probabilities.

Overall, then, we expect that if the fertility adaptation hypothesis holds, second-birth probabilities should increase as the duration of stay in the United States increases. Migration's effect on the probability of bearing a second birth should increase across birth cohorts as the gap between Chinese and US fertility levels widens ${ }^{7}$ (Hypothesis 4). Moreover, adapting to US society should also involve a decline in son preference because US norms on gender preference lead to a much more modest overrepresentation of male births (Dahl and Moretti 2008). As a result, we expect that son preference should diminish among Chinese migrants with respect to non-migrants (Hypothesis 5).

\subsection{Migration as a disruption to the fertility process}

The disruption hypothesis argues that migrating is a stressful process that depresses fertility around the time of migration, especially for international migrants (Milewski 2010). Difficulties in giving birth around migration are related to a number of factors, including spouses' physical separation (Chattopadhyay et al. 2006); uncertainty about the future, including job instability; and practical concerns that childbearing might impede economic success or that migration might result in a

\footnotetext{
7 Note that this effect is opposite to the one proposed by Hypothesis 3. The empirical analyses should clarify which effect predominates.
} 
temporary loss of or decrease in resources (Milewski 2007). Migration's disruptive effect can lead to birth postponement, and after migration's uncertainty or difficulties disappear, these females often catch up in fertility behavior (Goldstein et al. 2007).

A different situation emerges when migration is triggered by marriage, in which case migration should lead to higher first-birth probabilities just after migration because the couple starts a family when one member of the couple migrates (Hoem and Nedoluzhko 2008). However, once a control for the marriage's duration is made, this effect should disappear. Unfortunately, marriage migration cannot be identified in our analyses because age at first marriage is not available in the 2000 US census. However, our analyses of data from the Chinese International Migration Project for Fujianese migrants to the United States showed that marriage migration has a low prevalence in Chinese-US migration and is not a driver of the probability of having a birth during the year of migration. Overall, then, we expect that if the migration disruption hypothesis holds, a migrant's fertility level should decrease around migration time and recover afterward (Hypothesis 6).

\subsection{Migrant selection hypothesis}

In most countries, Chinese migrants' fertility is lower than that of other ethnic groups (Poston, Mao, and Yu 1994), but little research has seriously addressed their actual fertility selectivity (i.e., if migrants hold particular characteristics that lead to low fertility). Coleman and Dubuc (2010) and Abbasi-Shavazi and McDonald (2000) found that Chinese international migrants' fertility level was lower than natives and other ethnic groups in the UK and Australian context. However, the abovementioned researchers have not investigated which fertility level is lower, that of Chinese international migrants or that of non-migrants. 
Furthermore, most studies of the interrelationship between migration and fertility have discovered that migrants are negatively selected in terms of fertility with respect to non-migrants in the origin population (e.g., Goldstein and Goldstein 1983, Lindstrom and Saucedo 2002, Baizan 2017, Lindstrom 2003). Although this selection effect is generally difficult to prove empirically, some evidence of its existence has been demonstrated in different migration contexts, for example, Chinese Malaysian rural-to-urban migration (Goldstein and Goldstein 1983), long-term or settled Mexico-US migration (Lindstrom and Saucedo 2002), Ghana rural-to-urban migration (Chattopadhyay et al. 2006), and Senegal-Europe migration (Baizan 2017). Lindstrom (2003) confirmed that rural-to-urban migration in Guatemala is selective of migrants with some characteristics associated with lower fertility.

Considering that these analyses often include several socioeconomic controls, particularly educational level, these results may reflect unmeasured variables such as a migrant couple's stronger desire to achieve a higher socioeconomic status or preferences for smaller family size, compared with non-migrants. These types of variables, however, are often unavailable in migration quantitative data, like the China and US census examined here, potentially leading to endogeneity between the processes of migration and of fertility. In this article, migrants' unobserved characteristics are captured as a selection effect because they are related to both migration and fertility. Biased results can be obtained in the statistical analyses if proper control of these selection effects is not conducted (Lillard 1993).

The selection hypothesis posits that migration is selective of migrants with specific observed or unobserved characteristics that lead to lower fertility levels (Goldstein and Goldstein 1981, Lindstrom and Giorguli Saucedo 2007). These unobserved characteristics may include education (Wolf and Mulder, 2018), age at marriage, a tendency to postpone childbearing (Chattopadhyay et al. 2006), and a desire to achieve upward social mobility (Macisco et al., 1969). The social mobility aspiration might 
concern Chinese migrants as Chinese international migration is likely to involve selection associated with migrants' socioeconomic status, income, and education. Positive selection on one's socioeconomic status may be due to migration's high cost for Chinese households and US antiimmigration policy's restriction on lower-skilled migrants' migration. The above arguments lead us to expect that migration is selective of Chinese females of childbearing age with some (unobserved) characteristics that predict a lower fertility level than non-migrants (Hypothesis 7).

\section{China's family policy and migration policies in China and the US}

To understand the emancipation hypothesis, it is crucial to consider the evolution of family policies enacted in China, as well as changes in migration policies in both China and the United States. These two set of policies are summarized below.

\section{China's family policy}

China's birth control policy does not have a long history. In the early 1950s, birth control and abortion were discouraged in China, especially among women working in the public sector. ${ }^{8}$ However, starting in the 1970s, the Chinese government enacted the "later-longer-fewer (Wan-Xi-Shao)" policy, ${ }^{9}$ arguing that people should plan their fertility, to achieve a planned increase in total

\footnotetext{
8 "Measures to control abortion among women working in administrative departments and military forces (Health Department of Central government, April 20"th 1950 ), and "Measures to limit contraceptive and abortion (Health Department, December $31^{\text {st }}, 1952$ ).

9 The "later-longer-fewer" policy refers to a) postponed marriage age of 28 and 25 , respectively, for males and females of urban residence and 25 and 23, respectively, for males and females of rural residence; b) a four-year interval between births; and c) at most three and two children for rural and urban residents, respectively (Bongaarts and Greenhalgh 1985).
} 
population. ${ }^{10}$ Around 1980 , to further lower China's overall fertility level, a stricter birth control policy, the one-child policy, was enacted which stipulated that "one couple should have only one child" (see footnote 1). Over time, there were several policy changes for particular groups that were subject to special conditions, for instance, rural residents, minority ethnic groups, and economically disadvantaged families (Regulations on Population and Family Planning in Hebei, 1997), but the channels through which couples could have more births than allowed were very limited (i.e., by contributing a "social support" fee as a penalty) (the State Council, order no. 357).

\section{Chinese migration to the US}

The Chinese are the largest Asian population in the United States, accounting for $24 \%$ of Asian Americans (4.9 million), as of 2015 (Pew Research Center ${ }^{11}$ ). Unlike the Mexico-US migration system, the China-US migration system does not typically involve circular or return migration (Liang and Zhang 2004). Since the 1960s, US immigration policy has facilitated migration from China, having eliminated the previous quota system and permitting network migration (Immigration Act of 1965). Furthermore, in 1996, the United States allowed a set number of Chinese migrants affected by the onechild policy to claim asylum in the United States ("Illegal Immigration Reform and Immigrant Responsibility Act”, 1996). From 1978 to 2000, the Chinese government strictly controlled emigration, especially from the seven coastal provinces that had higher emigration rates (Chin 2003). Despite the tightened emigration policy, emigration, especially irregular emigration, increased due to foreign

\footnotetext{
${ }^{10}$ On July 8th, 1971, the State Council of China agreed on and enacted a "Report of Planned Family Policy," known as the No.51 document.

${ }^{11}$ López G. Ruiz N.G., and Patten E. (2017). Key facts about Asian Americans, a diverse and growing population. Factank, Sep 8, 2017.
} 
direct investment (Chin 2003). Policies aimed at controlling emigration and China's borders were enacted in 1985, 1992, and 1997 (Chin 2003). The combination of US immigration policy and Chinese emigration policy has had a positive net effect on total international movement: from 1970 to 1990 , there was a dramatic increase in Chinese migrants to the United States (Poston et al. 1994) - a vast migration flow analyzed in this article.

\section{Data and measurement}

This article compares data on Chinese migrants in the United States and non-migrants living in China. For Chinese migrants in the United States, we consider both the first and 1.5 generations, the latter composed of individuals who migrated before they were 15 years old. We focus on the period immediately before and during which the one-child policy was enforced in mainland China (1965 to 2005). For migrants, we use the 5\% sample of the 2000 US census and the 2005 American Community Survey and for non-migrants, the 2000 Chinese census and a subsample of China's $1 \% 2005$ National Population Sample Survey. ${ }^{12}$ We randomly resampled 1\% of non-migrant females for the sake of faster computation. The final sample included 19,209 non-migrants and 12,544 migrants. ${ }^{13}$

We identified females of reproductive age, 15-40 years ${ }^{14}$ (henceforth referred to as women), who were born between 1960 and 1990 in the People's Republic of China and were living in the United

\footnotetext{
12 US 1980 and 1990 census data are not employed because there is no information on the exact year of migration, making the construction of complete migration history impossible.

13 The results did not change substantively when a different $1 \%$ sample of non-migrants was used, meaning that the results are not sensitive to resampling from the original data.

14 China's 2000 census and 2005 1\% sample survey provided information on the number of children ever born to each woman. However, this information was available in neither the US 2000 census nor the 2005 American Community Survey.
} 
States in the survey year. We analyzed only women because male fertility is unavailable. ${ }^{15} \mathrm{We}$ constructed fertility histories for these women, from age 15 up to their first birth; from the first birth to the second birth; and from the second birth to the third birth; or to censoring. We used two criteria for censoring observations if no further births were observed - 20 years after the previous birth or being older than 40 years at the survey or census time - to avoid including mothers whose children had left the parental home. We selected one of the aforementioned conditions for censoring observations based on its chronological order. The median age for a Chinese son and daughter to leave the parental home was 24.9 and 24 years, respectively, during the 1980s, which is later than the median age for individuals in other countries such as Japan, the United States, Sweden, and France (Zeng et al. 1994). The reason for this late leaving is fourfold: (1) many Chinese remained in their parents' home after marriage in the 1980s (Zeng et al. 1994), (2) there was a serious housing shortage in the 1980s, especially in urban areas in China (Zeng et al. 1994), (3) the college enrollment rate in China was low from 1982 to 1990 (Yi et al. 1994), and (4) China's familial welfare regime made young individuals more reliant on parental resources (Nauck, Groepler, and Yi 2017). Thus, children were very likely to be present in their parents' household when their mothers turned 40 years old in China. Return migrants are not considered, which might only slightly bias the results since Chinese international migrants have a remarkably low return rate (Liang and Zhang 2004).

We reconstructed mothers' fertility histories by applying the own-child technique (Coleman and Dubuc 2010). We linked the first, second, and third child born to the mother by using information derived from the household roster, which contains the relationship of all individuals living in the

\footnotetext{
15 The disruption effect is likely to be higher for males because the separation typically ends when the female arrives at the destination.
} 
household to the household head and information on the number of children ever born, age of children, and their mothers' identification. ${ }^{16}$ To avoid reverse causation, the analyses include the approximate date when the mother decided to have a child, approximated as one year before the delivery, to account for the 9-month pregnancy period.

Figure 1 shows that Chinese women born between 1960 and 1990 encountered different fertility policies across their reproductive ages. The one-child policy roughly started in 1980 and ended on the first day of 2016. The white grids in Figure 1 represent the period without firm birth control policies. The period, 1974-1979, witnessed the "later-longer-fewer" policy. The darker area in Figure 1, between 1980 and roughly 1985, represents roughly the one-child policy's strictest version, and the lighter grids stand for several amendments to the one-child policy that varied across China. We observe that fertility decisions made by members of the cohorts born between 1960 and 1990 are heavily influenced by the one-child policy, although married women were under different policies for different lengths.

- Figure 1 about here -

Because census data provide no information on whether the members of a couple are only children, our estimates involve some inference, with upper (all couples fulfilled the condition of "both couple members being an only child") and lower (all couples fulfilled the condition of "neither member of the

\footnotetext{
16 According to the own-child technique, women who reported a different number of children compared with the number of children matched in the household would be excluded from the final sample. Following this logic, if we focus on women aged under 40 by the census or survey time, we drop $25 \%$ of non-migrant women.
} 
couple is an only child") bounds. ${ }^{17}$ Because the sampling framework of origin and destination country is not the same, before modeling the effect of migration status and fertility policy on the first, second, and third births, migrants and non-migrants were matched by a matching technique explained in the Online Appendix research note A2. ${ }^{18}$ To analyze the possible interrelationship between the processes of fertility and migration, we used structural-equation event history models with correlated unobserved heterogeneity of the type introduced by Lillard (1993). The endogeneity of fertility and migration was addressed by allowing unobserved heterogeneity to be correlated across the two processes. In that manner, we could control for shared unmeasured factors that simultaneously influence births and first migration. Furthermore, selection effects specific to each birth order were accounted for by modeling each birth order with one equation with a common heterogeneity component (Kravdal 2001). Equations 1, 2, and 3 refer to first, second, and third births respectively, and equation 4 refers to migration (Rabe-Hesketh \& Skrondal 2012).

$$
\begin{gathered}
\ln \left\{\frac{\operatorname{Pr}\left(y_{i t}^{1 B}=1 \mid X_{i t}, \varepsilon_{i}\right)}{1-\operatorname{Pr}\left(y_{i t}^{1 B}=1 \mid X_{i t}, \varepsilon_{i}\right)}\right\}=\beta_{1}+\beta_{2} x_{i t}+\beta_{3} w_{i t}+\varepsilon_{i} \\
\ln \left\{\frac{\operatorname{Pr}\left(y_{i t}^{2 B}=1 \mid X_{i t}, \varepsilon_{i}\right)}{1-\operatorname{Pr}\left(y_{i t}^{2 B}=1 \mid X_{i t}, \varepsilon_{i}\right)}\right\}=\beta_{1}+\beta_{2} x_{i t}+\beta_{3} w_{i t}+\varepsilon_{i} \\
\ln \left\{\frac{\operatorname{Pr}\left(y_{i t}^{3 B}=1 \mid X_{i t}, \varepsilon_{i}\right)}{1-\operatorname{Pr}\left(y_{i t}^{3 B}=1 \mid X_{i t}, \varepsilon_{i}\right)}\right\}=\beta_{1}+\beta_{2} x_{i t}+\beta_{3} w_{i t}+\varepsilon_{i} \\
\ln \left\{\frac{\operatorname{Pr}\left(y_{i t}^{M}=1 \mid X_{i t}, \lambda_{i}\right)}{1-\operatorname{Pr}\left(y_{i t}^{M}=1 \mid X_{i t}, \lambda_{i}\right)}\right\}=\beta_{1}+\beta_{2} w_{i t}+\lambda_{i}
\end{gathered}
$$

\footnotetext{
17 The two approaches lead to similar results of policy changes' effect on fertility, except that the coefficients of "more than 1 child allowed" under the two scenarios are different for the first birth equation. 18 In the matching technique, we apply weights similar to the population weights. The matching procedure does not inflate the total sample size or number of migrants.
} 
In these equations, the subscript $i$ refers to the woman, and $t$ refers to each time unit (i.e., year). The $X_{i}$ denotes a vector of covariates, $x_{i t}$ denotes the fertility policy and migration status variable, and $w_{i t}$ is a set of control variables. The left side of the equations is the logarithm of the odds conditional on a set of covariates and the error term (heterogeneity term). The values of a time-varying covariate change at discrete times in the time period leading to each birth and are constant over the time span between those changes. To apply discrete-time event history models, four person-year files were constructed, one for each process considered. Women enter the risk set of the processes of first migration and first birth when they reach 15 years old and leave it when they experience these events, when they reach 40 years old, or in 2000/2005 (census or survey time), whatever comes first. Similarly, women enter the risk set of subsequent births once they have had a child of the previous birth order and leave the process when one of the following conditions is met: bearing a second (third) child, reaching age 40 , or 2000/2005 (census or survey time), whatever comes first.

We applied logistic regression. The dependent variable was coded as 1 for the corresponding birth order and 0 for not yet having that birth order. The women-specific random variables $\varepsilon$ and $\lambda$ capture unobserved heterogeneity and are assumed to have a joint bivariate normal distribution:

$$
\left(\begin{array}{l}
\varepsilon \\
\lambda
\end{array}\right) \sim N\left(\left(\begin{array}{l}
0 \\
0
\end{array}\right), \quad\left(\begin{array}{cc}
\sigma_{\varepsilon}^{2} & \rho_{\varepsilon \lambda} \\
\rho_{\varepsilon \lambda} & \sigma_{\lambda}^{2}
\end{array}\right)\right)
$$

in which $\rho_{\varepsilon \lambda}$ is the correlation between the unobserved heterogeneity terms of the processes. The model estimation was performed using full-information maximum likelihood and implemented in the package aML (Lillard and Panis 2000). Repeated fertility outcomes for each woman and the inclusion of a different set of variables for fertility and migration allowed us to identify the standard deviations of the error terms in the system of equations (Lillard and Panis 2000). However, the standard deviation 
of the unobserved heterogeneity term in the migration process was fixed at 3 because we only have information on first-time migration. Identification was achieved by including variables assumed to be exogenous (see below). We selected these variables because they are related to migration behavior but not directly related to fertility decision-making; thus, they facilitate the identification of the heterogeneity term in the migration equation.

The primary variables explaining fertility differences are migration status and fertility policy. Controls include age, birth cohort, and women's educational attainment. "Policy and migration status" denotes whether a) a particular birth parity was allowed when the individual's place of residence at a given point in time was China, b) the Chinese woman was in the year migrating to the United States for the first time ${ }^{19}$; c) she was living in the United States as a first-generation migrant; and d) she belonged to the 1.5 generation who came to the United States before 15 years old. Because of substantial differences between Chinese regions, regional differences in family policies are analyzed from 287 documents on "population and planned birth regulation" and covered in point (a) in the preceding list (see Table A1). We introduce province-specific fertility regulations (Online Appendix Table A1) in 22 provinces, three municipalities (except Chongqing, which was integrated into Sichuan Province), and five autonomous regions; thus, this research covers almost all areas of mainland China. We also separate the likelihood of having birth by parity because each birth parity is treated differently by China's policies. The reference group reflects the strictest family policy for that particular birth parity.

To capture migration's impact on national-level economic development and immigration and emigration policy after 1965, we included several economic indicators, such as China's gross domestic

${ }^{19}$ Having a category "at the year of migration" isolates the possible simultaneity of migration and fertility. 
product (GDP) real value and GDP growth rate, the GDP ratio of China and the United States, the US unemployment rate, immigration/emigration policy at origin and destination, percent urban, and land policy $^{20}$ in China. We observed approximately five turning points in Chinese emigration policy from 1965 to 2005: (1) the 1978 open-door policy that ended restrictions on international migration, (2) the first set of migration laws on border control and applications for passports in November 1985, (3) an official document that ordered coastal provinces to curb irregular flows in April 1992, (4) a modified criminal law that added harsh penalties for human smuggling in 1997, and (5) a passport policy that formalized the passport applications in 1999 (see Chin [2003] for details).

\section{Results}

In Table 1, we examine the emancipation hypothesis by assessing the effect of the fertility policy and migration status on first, second, and third births, controlling for age, time since previous birth, birth cohort, and education (Hypothesis 1). Timing effects (Hypothesis 2) are tested with interaction terms between migration status and age (for first birth) and between migration status and duration since last birth (for second and third births; Table 1 [Models 1 to 4] and Figures 2 and 3). To test changes across birth cohorts in the emancipation effect, an interaction between migration status and birth cohort is included in Table 1 (Models 3 and 4) and in Figure 4, allowing us to visually assess the hypothesis that the emancipation effect diminishes across birth cohorts (Hypothesis 3). In Table 2, we introduce the time since migration in Models 5 to 8 to explore the adaptation hypothesis. However, before examining these hypotheses, we must clarify whether selection effects influence our results.

\footnotetext{
20 Since 1983, this land policy has granted a stable usage of farmland to individual households for as long as 15 years without changing the owner.
} 


\subsection{Selection effects}

In some models, the fertility equations are jointly estimated with a migration equation with controls for several demographic and economic indicators and for migration policy at origin and destination. Therefore, we present models that exclude (see Models 1 and 3) and include (see Models $2,4,5,6,7$, and 8 ) the unobserved heterogeneity components for fertility and migration and their correlation (see "standard deviations and correlation between heterogeneity components" panel). Although these models are not directly comparable, they show the impact of selection effects on our results.

Unobserved differences between individuals in fertility and migration are attributed to several factors captured by the heterogeneity terms. As discussed, unobserved factors may be associated with socioeconomic mobility aspirations, fertility intentions, and family orientation. Although some Chinese female migrants moved to the United States for family reunification reasons, there might also be socioeconomic motivations. The results show that the standard deviation of the heterogeneity component for fertility is statistically significant, indicating that, indeed, unobserved factors drive this process. Including the heterogeneity component for fertility, thus, corrects for selection into a given birth order (e.g., women at risk of a second birth obviously must have had a first birth). Moreover, the heterogeneity terms of the fertility and migration processes are negatively correlated (correlation $=$ 0.66 as in Model 2 and 6), implying that women who were more likely to migrate were also less likely to bear many children. Migration is, thus, selective of migrants with some unobserved characteristics that predict a relatively low fertility level, as expected in Hypothesis 7. 
Moreover, migrant's negative selection in terms of fertility is consistent with the increasing migration probabilities displayed by the more recent birth cohorts (which also display lower fertility levels than previous birth cohorts). Other results of the migration equation show the expected strong positive effects of China's migration policies, GDP growth, and urbanization rate. All these variables show relatively minor differences between the models that account for unobserved heterogeneity and those that do not. By contrast, the differentials in migration probabilities by a woman's education level disappear after accounting for unobserved heterogeneity, suggesting that the unobserved heterogeneity is closely linked to women's educational attainment. The increase across birth cohorts in migration probabilities is severely underestimated if unobserved heterogeneity is not accounted for: The odds ratio of migration for women born from 1975 to 1979, for example, is approximately six times higher than that for women born from 1960 to 1964, accounting for heterogeneity, compared with 1.80 times higher if this control is not performed.

Regarding the fertility processes (Table 1, equations 1, 2, and 3), we observe the expected effects of age and duration since previous birth and the expected strong negative effects of education and birth cohort (i.e., fertility declines across birth cohorts). However, the impact of these last two variables is underestimated if we do not account for unobserved heterogeneity. More crucially for our purposes, the comparison between models accounting for selection and models not accounting for selection (i.e., between Models 1 and 2 and between Models 3 and 4) provides different results for the variable “migration status." Thus, the results of Models 1 and 3 show migration's large positive impact on second and third births, but not on first birth. However, when unobserved heterogeneity is considered, migration's positive effect is even larger for second and third births, and for first births, migration's effect becomes positive. Failure to account for correlated unobserved heterogeneity would have led to 
a substantial underestimation of migration's "emancipation effect" on fertility. For this reason, the remainder of this discussion focuses on models that account for unobserved heterogeneity. ${ }^{21}$

\subsection{Emancipation hypothesis}

Model 2 in Table 1 shows the strong positive effect that being "after migration" has on second and third births (odds ratio of 20.5 and 9.3, respectively, shown in equations for second and third births), but less so on first births (odds ratio 1.7). As already mentioned, Model 2 controls for the historical decline in fertility by including the birth-cohort effect and for the effect of being subject (or not) to China's family policy. Therefore, the positive effect of the category "after migration" can be considered evidence supporting the emancipation effect (Hypothesis 1). Moreover, compared with women living in China, 1.5-generation migrants' odds of having a second birth were 3.4 times higher, consistent with the emancipation effect. In Figure 2, the emancipation effects' scale in terms of the predicted probabilities of bearing a child is relatively large. The emancipation effect is especially strong for second births, which were the one-child policy's main target. Third births were normally not allowed by the one-child policy, leading to a strong relative emancipation effect; however, in absolute terms, the emancipation effect is small because fertility ideals were mostly limited to an average of two children per woman (Basten and Gu 2013; Gietel-Basten 2019). The conditional annual probability of the first birth is similar for a 1.5-generation migrant and a non-migrant, but the probability of a second and third birth is higher for a 1.5-generation migrant than for a non-migrant.

\footnotetext{
21 In Table 2 (Model 7 and 8), we show that for two groups of people with different education levels (i.e., at most primary school and secondary education and above), the selection effects are both negative, with a slightly stronger negative effect for groups with less education.
} 
1.5-generation migrants' fertility should reflect a situation of individuals partly socialized in the United States, where Chinese family policies do not apply.

\section{- Figure 2 about here -}

Even simple survival curves with no controls show that ten years after a previous child, approximately $73 \%$ of migrants had a second child, compared with only $50 \%$ of non-migrants (Figure 3). ${ }^{22}$ By contrast, only approximately one fourth of both migrants and non-migrants had a third child. The effects on first birth appear more complex because childlessness at age 40 among migrants is much higher $(25 \%)$ than among non-migrants $(6 \%)$. These results without controls likely reflect both selection effects and fertility's comparatively smaller positive effect on having migrated to a new context.

- $\quad$ Figure 3 about here -

A complementary method to assess the emancipation effect is by plotting the simulated probabilities of childbearing for a migrant woman compared with a non-migrant woman (Figure 4, based on Model 2). Figure 4 clearly shows migration's immediate boosting effect on fertility for all birth orders. Notably, birth probabilities sharply increase just after migration, suggesting that the emancipation effect dominates over an adaptation effect because adaptation to a new context normally

\footnotetext{
22 For migrants, only those who migrated before first birth are included. Approximately, $75 \%$ of migrants migrated before the first birth.
} 
involves time. Furthermore, this result supports Hypothesis 2 that once at destination, migrants should have an earlier timing of fertility. Notably, the results presented in Figure 4 include an interaction effect between the timing of each birth order and the variable "policy and migration status." Consistent with our Hypothesis 2, simple calculations without controls show that migrants had shorter birth intervals between births than did non-migrants: the intervals between first and second birth for nonmigrants, first-generation migrants and 1.5-generation migrants were 3.8 year, 3 years and 2.6 years, respectively, suggesting an emancipation effect from Chinese policies that prescribed a minimum length of birth intervals.

- $\quad$ Figure 4 about here -

Finally, the results of Figure 4 (based on Model 4) show that the emancipation effect declines across birth cohorts, especially for second births, because of the declining trend in fertility and fertility intentions in China, supporting Hypothesis 3. This trend is, to a large extent, independent of China's fertility policies, as shown by the very low fertility levels attained in China after the restrictions for a second child were eliminated in 2016 (Gietel-Basten 2019). Notably, the emancipation effect's strength greatly differs by women's education level (see Figure A3 in the Online Appendix). The predicted probability of bearing a second child for women with university degrees living in China was particularly low, and that of a third birth is nearly nil. ${ }^{23}$ It is likely that many of these women worked

\footnotetext{
${ }^{23}$ From 1965 to 2005, the sum of the annual predicted probabilities of having a second child estimated from the model is approximately 0.0718 (or 7\%) for women born between 1950 and 1990 with university degrees. This rate is slightly higher than the 1999 annual birth rate (2\%) for women between 15 and 49 with university degrees estimated from China's 2000 census, which means that our estimate is robust.
} 
in the public sector, where having a second or third birth involved the risk of losing their jobs, according to the one-child policy.

- Table 2 about here -

\subsection{Adaptation and disruption effects}

In Model 5 (Table 2), the odds of bearing a first, second, and third birth substantially increase as the duration of stay in the United States increases, providing support for Hypothesis 4. Duration's effect is particularly strong for second births: Migrants' odds of having a second birth were 14 times as high as that for non-migrants during the 3 years after migration and increased to 32 times as high as that for non-migrants beyond the third year after migration. Moreover, the year of migration involves a reduction in the odds of bearing a child only in the case of first births (odds ratio $=0.62$ ), and in the cases of second (odds ratio $=5.4$ ) and third births (odds ratio $=1.2$ and not significant), there is even an increase in the odds. These results are supporting evidence that migration's disruption effect is limited to first births and a relatively rapid adaptation to US society (Hypothesis 4, 5, and 6). Of course, it is difficult to disentangle these effects from the aforementioned very strong emancipation effect. Adapting to US fertility should involve an increase in the fertility of migrants (vs. non-migrants) for more recent birth cohorts, reflecting the increasing gap between declining fertility preferences in China and relatively stable and moderate fertility levels in the United States. Indeed, as already mentioned, the interaction between migration status and birth cohort shows migration's declining effect over birth cohorts, especially for second births, which likely reflects a dominance of the emancipation effect over any adaptation effect, especially for the older birth cohorts who were strongly affected by China's onechild policy. 
Using the 2000 US census, Almond and Edlund (2008) showed that son preference was evident in the third birth for Chinese migrants, compared with whites. In our results, having had one or two female births predicted a lower probability of having the next child for Chinese migrants living in the United States than for those living in China, supporting Hypothesis 5. Thus, the odds of second births for women living in China were 1.15 if the first child was a girl. However, the odds reduced to 0.99 for first-generation Chinese migrants in the United States (Model 6). Even more striking is that the odds for third births were 4.47 if the two previous births were females and decreased to 0.57 for firstgeneration migrants with two previous female births. This finding implies a detachment from son preference noted in China and an adaptation to US norms.

\section{Discussion and conclusions}

China's one-child policy ended on January 1, 2016, halting a decades-long policy that no other nation had dared to enact. Given the impact of this and other family policies in China, how did the act of international migration change Chinese women's fertility levels? This article has examined how Chinese migrants to the United States behaved under the following conditions: they were freed from China's birth restrictions, they faced the difficulties of migration, and they were exposed to different fertility conditions in the United States. According to our literature review, our article is the first to explicitly test the "emancipation hypothesis" proposed by Hwang and Saenz (1997) by comparing Chinese international migrants' fertility level with that of non-migrants in China, using individuallevel data and considering selection effects.

This comparison offers a number of key findings. First, our results confirm the "emancipation" effect and show that migration to the United States sharply increased Chinese migrant women's 
probability of having a first, second, and third birth, compared with non-migrants in China. Moreover, migration's positive effect declined across birth cohorts, consistent with a decline in fertility intentions in China. However, migration was also associated with a delay in first birth timing and a higher overall proportion of childlessness, linked to the strong migrant selection along with several unmeasured attributes.

Second, our analyses illustrated a case of migration from a context with very low fertility to one with "replacement" fertility levels. Until recently, migrating from a country of lower fertility to a country with higher fertility has been an exceptional situation, but it is likely to become more common (Yeung et al. 2018; Lima et al. 2018). On the one hand, several post-industrial societies display fertility levels of approximately two children per woman, and several other advanced countries have increased their fertility levels in recent decades (Sobotka 2017). Further evolution of family policies that help reconcile careers and childbearing may reinforce this trend in highly developed societies, which increasingly offer conditions conductive to replacement-level fertility (Esping-Andersen and Billari 2015; Myrskylä, Kohler, and Billari 2009). On the other hand, several Asian countries, including China, South Korea, Japan, Thailand, and Vietnam, display low or very low fertility levels (Jdanov and Sobotka 2019). Several newly industrialized counties in South Asia (Yeung et al. 2018) and Latin America (Lima et al. 2018) are also likely to experience these conditions in the next few decades, making emigration flows from countries with very low fertility more common in the future. Although these countries have not experienced family policies so restrictive as those of mainland China, the prevalent social and economic conditions (including policy effects) often result in low or very low fertility levels (McDonald, 2006; McDonald, 2000). This article shows that emigration from very low fertility countries may result in substantial increases in fertility for the individuals involved. Moreover, 
the literature analyzing the adaptation hypothesis points to a negative relationship between the length of stay in the United States and fertility (see Dubuc 2012), based on the case of migrants from origin countries with higher fertility levels than the destination country. In China-US migration, however, where the origin country's fertility is lower than that of the destination country, we find that international migration has a larger positive effect on the probability of having a second birth for older cohorts than for younger cohorts.

Third, our results suggest that Chinese international migration is selective of migrants with lower fertility, as has been observed in other contexts (Abbasi-Shavazi and McDonald 2000); Coleman and Dubuc 2010). We did not find evidence, however, that Chinese migration to the United States was selective of migrants with higher educational attainment. By contrast, our results show that migration is selective of migrants with some unmeasured factors leading to lower fertility than non-migrants. Given that these factors could not be directly observed, we can only speculate on their link with, for example, migrants' urban origin or upward social mobility aspirations. However, our results show that not including the effects of these unmeasured factors led to a substantial underestimation of migration's effect on fertility. Given international migration's highly selective nature and the data limitations that preclude a more explicit measurement of all relevant factors involved, further research should examine migration's effect on fertility to properly account for selection effects. Further research could also link the "emancipated" fertility of Chinese migrants in the United States with marriage migration when information such as age at marriage is available. It is possible that there is a lag effect in adapting to the fertility norm at destination, which can be tested only when more recent data are available at the origin and destination country. 


\section{Acknowledgement}

Our sincere gratitude goes to the editor and two anonymous reviewers for their comments on an earlier version of this article and their help during the editorial process. 


\section{Reference}

Abbasi-Shavazi, M. J., and P. McDonald. 2000. "Fertility and Multiculturalism: Immigrant Fertility in Australia.” International Migration Review 34(1): 215-42.

Adser`a, A., and A. Ferrer. 2016. "The Fertility of Married Immigrant Women to Canada." International Migration Review 50(2): 475-505.

Almond, D., and L. Edlund. 2008. "Son-biased Sex Ratios in the 2000 United States Census." Proceedings of the National Academy of Sciences 105(15): 5681-82.

Baizan, P. 2017. "How International Migration Impacts Fertility in the Origin Country? The Role of Social Capital Abroad." In Population Association of America Annual Meeting. Chicago.

Basten, S., and Gu, B. 2013. Childbearing Preferences, Reform of Family Planning Restrictions and the Low Fertility Trap in China. University of Oxford, Oxford Centre for Population Research: Working Paper \#61.

Bongaarts, J., and S. Greenhalgh. 1985. "An Alternative to the One-child Policy in China." Population and Development Review 11(4): 585-617.

Cai, Y. 2010. “China’s Below-replacement Fertility: Government Policy or Socioeconomic Development?” Population and Development Review 36(3): 419-40.

Chattopadhyay, A., M. J. White, and C. Debpuur. 2006. "Migrant Fertility in Ghana : Selection versus Adaptation and Disruption as Causal Mechanisms." Population Studies 60(2): 189-203.

Chin, J. K. 2003. "Reducing Irregular Migration from China.” International Migration 41(1): 49-72.

Coleman, D. A., and S. Dubuc. 2010. "The Fertility of Ethnic Minorities in the UK, 1960s2006.” Population Studies 64(1): 19-41.

Dahl, G. B., and E. Moretti. 2008. "The Demand for Sons.” Review of Economic Studies 4: 1085-120.

Djundeva, M., P. A. Dykstra, and T. Emery. 2019. "Family Dynamics in China and Europe in the Last Half-century." Chinese Journal of Sociology 5(2): 143-72.

Dubuc, S. 2012. "Immigration to the UK from High-fertility Countries: Intergenerational Adaptation and Fertility Convergence.” Population and Development Review 38(2): 353-68.

Echeverria-Estrada, C., and J. Batalova. 2020. "Chinese Immigrants in the United States." Migration Policy Institute, Washington. 
Esping-Andersen, G., and F. C. Billari. 2015. “Re-theorizing Family Demographics.” Population and Development Review 41(1): 1-31.

Feeney, G., and F.Wang. 1993. "Parity Progression and Birth Intervals in China: The Influence of Policy in Hastening Fertility Decline.” Population\& Development Review 19(1): 61-101.

Gietel-Basten, S. 2019. The "Population Problem" in Pacific Asia. Oxford, UK: Oxford University Press.

Goldstein, S., and A. Goldstein. 1981. "The Impact of Migration on Fertility: An 'Own Children' Analysis for Thailand.” Population Studies 35(2): 265-84.

— Using Life History Data.” Population Studies 35(2): 265-84.

Goldstein, A., M. White, and S. Goldstein. 1997. "Migration, Fertility, and State Policy in Hubei Province, China.” Demography 34(4): 481-91.

Goodkind, D. 2017. "The Astonishing Population Averted by China's Birth Restrictions: Estimates, Nightmares, and Reprogrammed Ambitions.” Demography 54:1375-400.

Gu, B., F. Wang, Z. Guo, and E. Zhang. 2007. "China's Local and National Fertility Policies at the End of the Twentieth Century." Population and Development Review 33(1): 129-48.

Hoem, J. M., and L. Nedoluzhko. 2008. "Marriage Formation as a Process Intermediary between Migration and Childbearing." Demographic Research 18(21): 611-28.

Hwang, S.-S., and R. Saenz. 1997. "Fertility of Chinese Immigrants in the U.S.: Testing a Fertility Emancipation Hypothesis.” Journal of Marriage and Family 59(1): 50-61.

Jdanov, D., and T. Sobotka. 2019. "Human Fertility Collection.” Max Planck Institute for Demographic Research (Germany) and Vienna Institute of Demography (Austria).

Kravdal, Ø. 2001. “The High Fertility of College Educated Women in Norway.” Demographic Research 5:187-216.

Kulu, H. 2005. "Migration and Fertility: Competing Hypotheses Re-examined." European Journal of Population/Revue Europeenne de Demographie 21(1): 51-87.

Liang, Y., Y. Yi, and Q. Sun. 2014. "The Impact of Migration on Fertility under China's Underlying Restrictions: A Comparative Study between Permanent and Temporary Migrants." Social Indicators Research 116(1): 307-26.

Liang, Z., and C. Miao. 2013. "Migration within China and from China to the USA: The 
effects of migration networks, selectivity, and the rural political economy in Fujian Province." Population Studies 67(2): 209-23.

Liang, Z, and T. Zhang. 2004. "Emigration, Housing Conditions, and Social Stratification in China." International Migration Review 38(2): 686-708.

Lillard, L. A. 1993. "Simultaneous Equations for Hazards: Marriage Duration and Fertility Timing." Journal of Econometrics 56(1-2): 189-217.

, and C. W. A. Panis. 2000. Multiprocess Multilevel Modeling: AML Version 2 User's Guide and Reference Manual, EconWare, Los Angeles, California, United States.

Lima, E. E. C., K. Zeman, T. Sobotka, M. Nathan, and R. Castro. 2018. "The Emergence of Bimodal Fertility Profiles in Latin America." Population and Development Review 44: 723-43.

Lindstrom, D. P., and S. G. Saucedo. 2002. "The Short- and Long-term Effects of U.S. Migration Experience on Mexican Women's Fertility." Social Forces 80(4): 1341-68.

2003. "Rural-Urban Migration and Reproductive Behavior in Guatemala." Population Research and Policy Review 22(4): 351-72.

— Maintenance, and Mexico-U.S. Migration. "Demographic Research 17(28): 821-58.

Logan, J. R.,W. Zhang, and R. D. Alba. 2002. "Immigrant Enclaves and Ethnic Communities in New York and Los Angeles.” American Sociological Review 67(2): 299-322.

L'opez, G., N. G. Ruiz, and E. Patten. 2017. "Key facts about Asian Americans, a diverse and growing population.” Factank: Pew Research Center, Sep 8, 2017. https://pewrsr.ch/ 2lheXin

McDonald, P. 2000. "Gender Equity, Social Institutions and the Future of Fertility.” Journal of Population Research 17(1): 1-16.

. 2006. "Low Fertility and the State: The Efficacy of Policy." Population and Development Review 32(3): 485-510.

Milewski, N. 2007. "First Child of Immigrant Workers and Their Descendants in West Germany: Interrelation of Events, Disruption, or Adaptation?.” Demographic Research 17(29): 859-96.

2010. Fertility of Immigrants: A Two-generational Approach in Germany in Demographic Research Monographs. Berlin/Heidelberg, Germany: Springer-Verlag Berlin Heidelberg. 
Myrskyla, M., H.-P. Kohler, and F. C. Billari. 2009. “Advances in Development Reverse Fertility Declines." Nature 460(7256): 741-43.

Nauck, B., N. Groepler, and C. C. Yi. 2017. "How Kinship Systems and Welfare Regimes Shape Leaving Home: A Comparative Study of the United States, Germany, Taiwan, and China." Demographic Research 36(1): 1109-48.

Poston, D. L., Jr., M. X. Mao, and M.-Y. Yu. 1994. "The Global Distribution of the Overseas Chinese around 1990.” Population and Development Review 20(3): 631-45.

Rabe-Hesketh, S., and A. Skrondal. 2012. Multilevel and Longitudinal Modeling Using Stata. 3rd ed. College Station, TX: Stata Press.

Sobotka, T. 2017. "Post-transitional Fertility: The Role of Childbearing Postponement in Fuelling the Shift to Low and Unstable Fertility Levels." Journal of Biosocial Science 49(S1): S20-45.

Wang, F. 2015. "China's Long Road toward Recognition of Below-replacement Fertility.” In Low and Lower Fertility, eds. R. R. Rindfuss and M. K. Choe. Cham, Switzerland: Springer International Publishing, 15-31.

Wong, M. G. 1995. "Chinese Americans.” In Asian Americans: Contemporary Trends and Issues, eds. P. G. Min. Thousand Oaks: Sage, 58-94.

World Bank. 2015. Fertility Rate, Total (Births per Woman)—China. https://data.worldbank. org/indicator/SP.DYN.TFRT.IN?locations $1 / 4 \mathrm{CN}$.

Wolf, K., and C. H. Mulder. 2018. "Comparing the fertility of Ghanaian migrants in Europe with nonmigrants in Ghana." Population, Space and Place 25(2): e2171.

Yang, X. 2000. "The Fertility Impact of Temporary Migration in China: A Detachment Hypothesis.” European Journal of Population 16:163-83.

Yeung, W., S. Desai, and G. Jones. 2018. "Families in Southeast and South Asia." Annual Review of Sociology 44(1): 469-95.

, and Z. Mu. 2019. "Migration and marriage in Asian contexts." Journal of Ethnic and Migration Studies 46(14):2863-879.

Zhao, Z., and G. Zhang. 2018. "Socioeconomic Factors Have Been the Major Driving Force of China's Fertility Changes Since the Mid-1990s.” Demography 55(2): 733-742.

Zheng, Z., Y. Cai, F. Wang, and B. Gu. 2009. "Below-Replacement Fertility and Childbearing Intention in Jiansu Province, China." Asian Population Studies 5(3): 329-347. 
Zhou, M., and Y. S. Xiong. 2005. "The Multifaceted American Experiences of the Children of Asian Immigrants: Lessons for Segmented Assimilation.” Ethnic and Racial Studies 28(6): 1119

Zeng, Y., A. Coale, M. Kim, Z. Liang, and L. Liu. 1994. "Leaving the Parental Home: Census-based Estimates for China, Japan, South Korea, United States, France, and Sweden." Population Studies 48(1): 65-80. 
Figure 1: One-child policy by woman's age and cohort

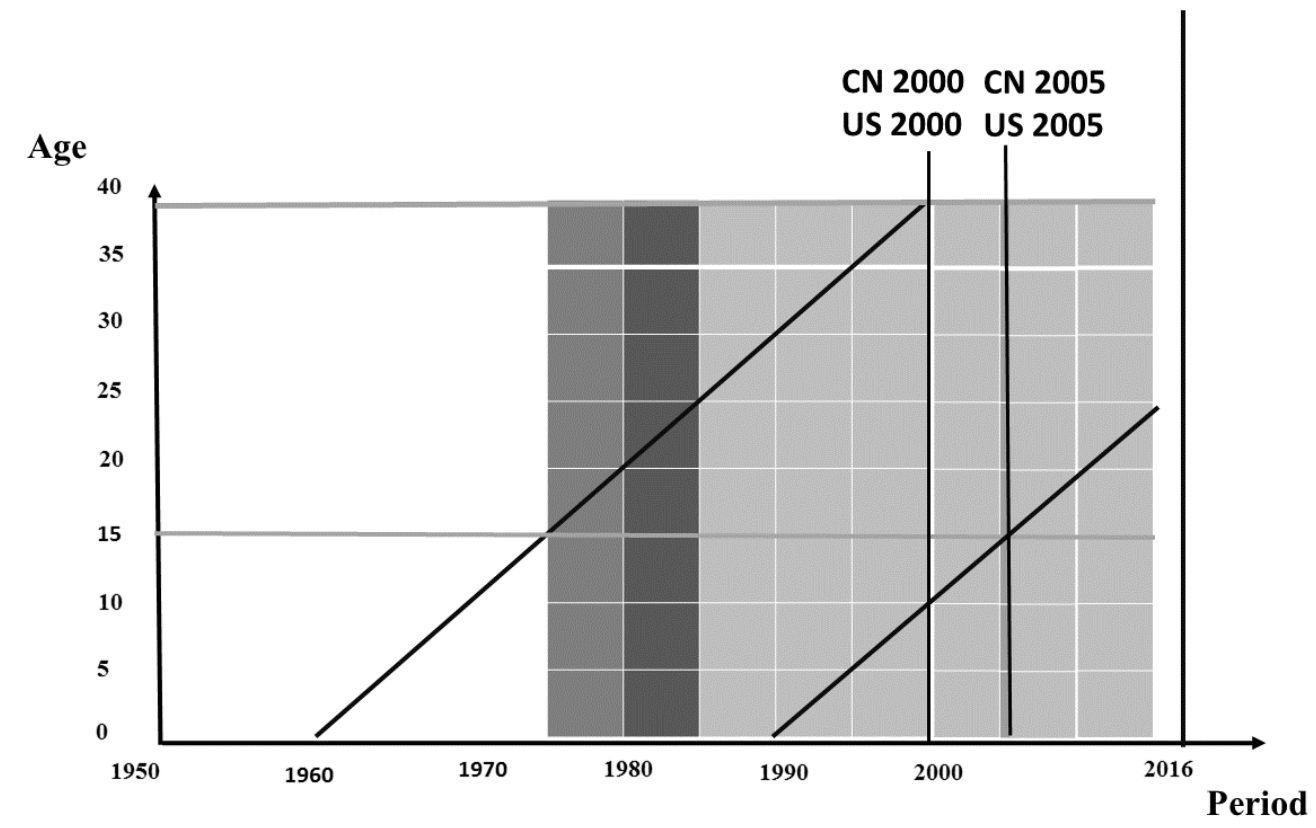

modified one-child policy

without restrctions

end of one child policy

later-longer-fewer

reproductive age

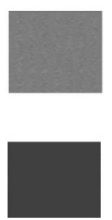

one-child policy 
Figure 2. Conditional annual probabilities of the first, second and third births for Chinese non-migrants, first generation migrants and 1.5 generation migrants.
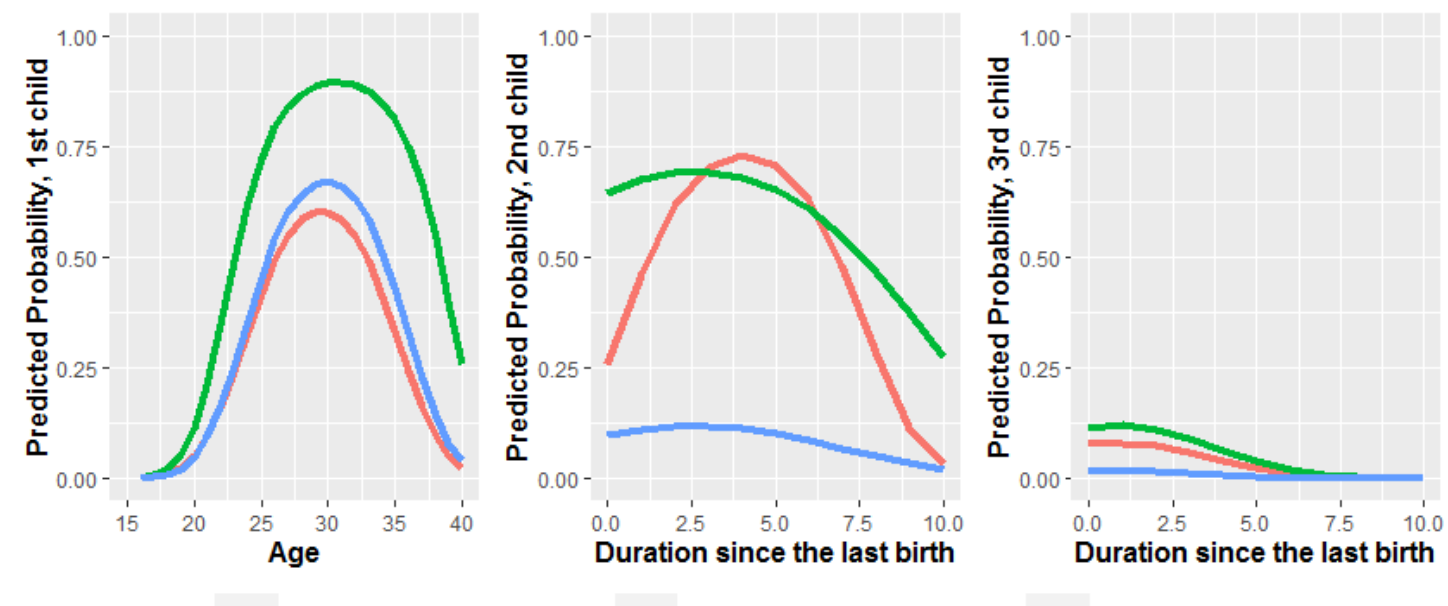

1.5 generation migrants $\quad$ first generation migrants

non-migrant

Note: Controls for age, age squared, birth cohorts, educational level and interaction term between age and migration status, duration since last birth and migration status are included. Model specification as Model 2 in Table 1. 
Figure 3. Survival curves of second and third births for migrants and for non-migrants, by duration since the last birth
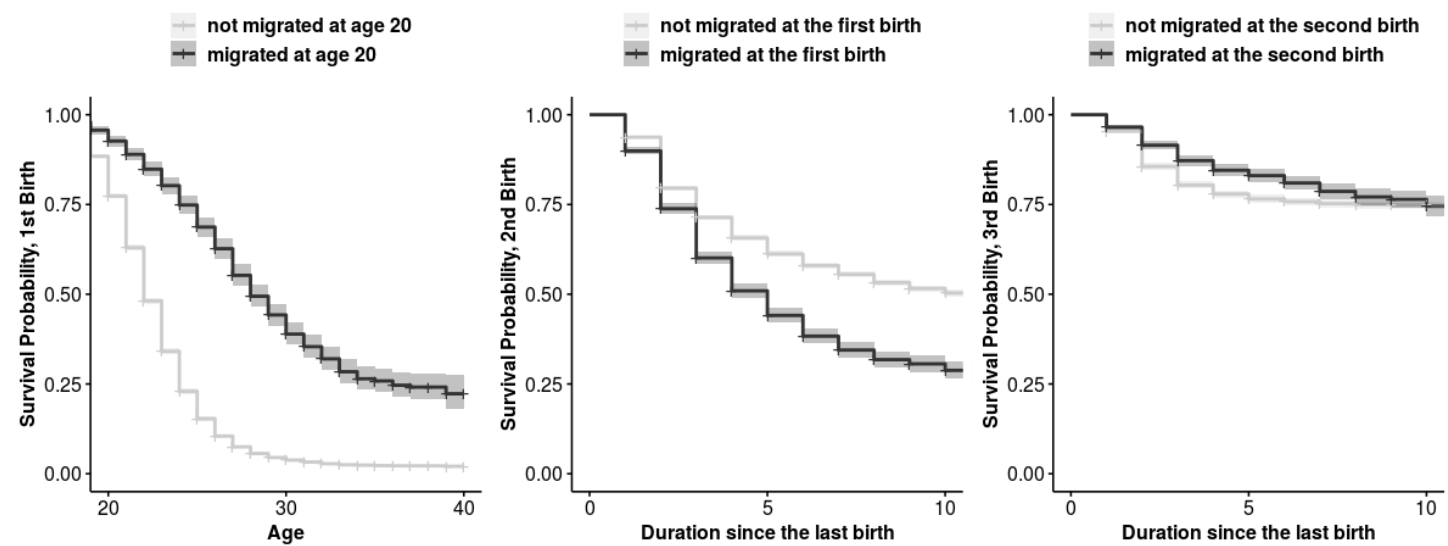

Note: The age range is from 15 to 40, i.e., the reproductive ages. No controls were included. Only stratification of migrant and non-migrant is included in the model specification. Confidence intervals are presented in the shadowed areas. The survival probabilities for first birth are plotted for those who migrated before age 20 and others who had not migrated at age 20 . 
Figure 4. Simulated conditional annual probabilities of first, second and third birth by migration status and birth cohort for a hypothetical migrant who migrated at age 30 and a non-migrant woman. Migration occurs 3 years after previous birth.
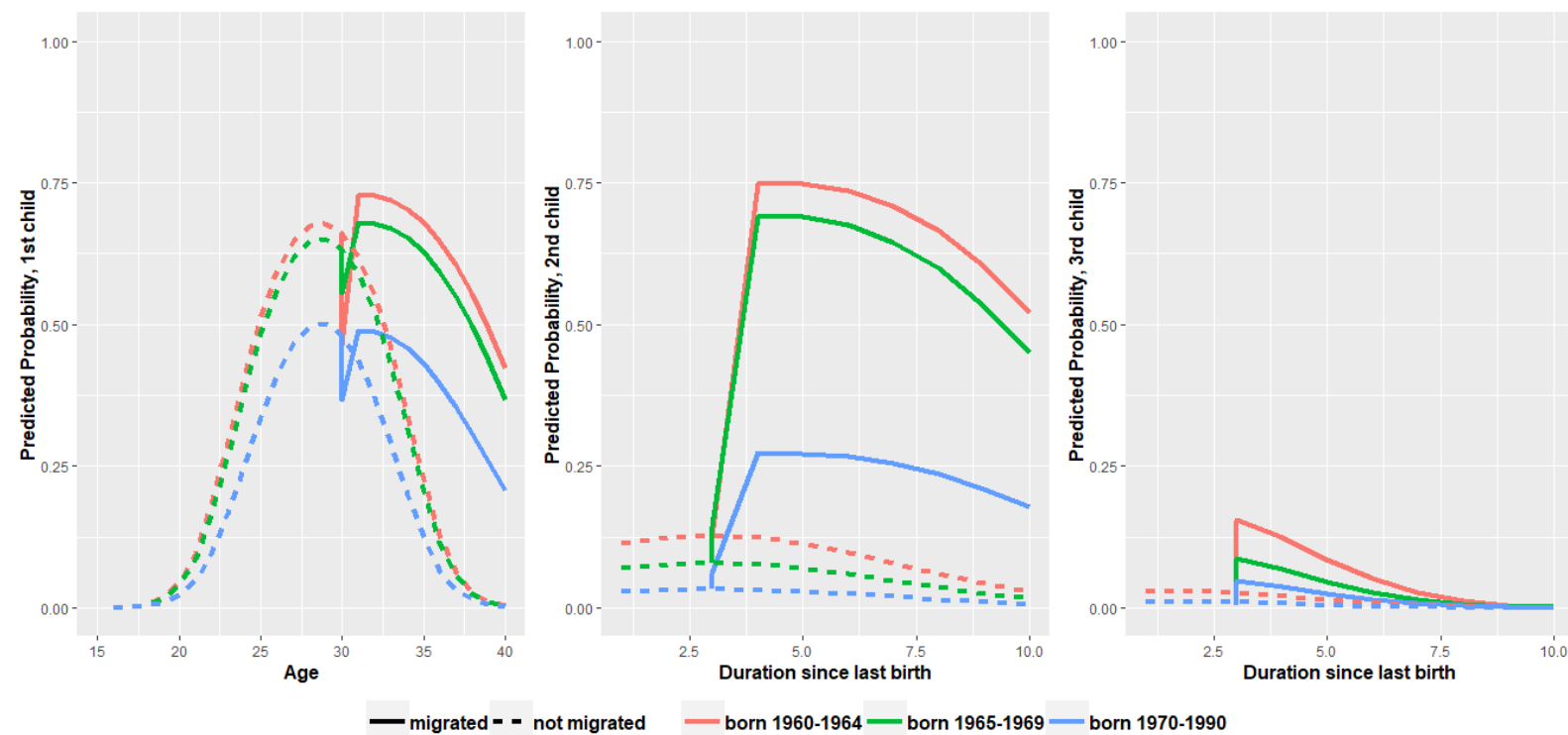

— born 1960-1964 — born 1965-1969 — born 1970-1990

Note:

Controls for age, age squared, birth cohort, educational level, policy and migration status, an interaction term between birth cohort and migration status, and an interaction term between age, age squared (or duration since last birth and its squared term) and migration status are included. For the third births, we do not include a separate category for the year of migration due to limited cases of this condition. Unobserved heterogeneity and correlation between the processes of fertility and migraton are also considered in the model specification. Model specification as Model 4. 
Table 1: Event-History Models for First, Second and Third Birth, and First Migration from China to US

\begin{tabular}{|c|c|c|c|c|c|c|c|c|}
\hline \multirow{2}{*}{ Equation 1 - First Birth } & \multicolumn{2}{|c|}{$\begin{array}{l}\text { Model } 1 \\
\text { Odds Ratio }\end{array}$} & \multicolumn{2}{|c|}{$\begin{array}{l}\text { Model } 2 \\
\text { Odds Ratio }\end{array}$} & \multicolumn{2}{|c|}{$\begin{array}{l}\text { Model } 3 \\
\text { Odds Ratio }\end{array}$} & \multicolumn{2}{|c|}{$\begin{array}{l}\text { Model } 4 \\
\text { Odds Ratio }\end{array}$} \\
\hline & & & & & & & & \\
\hline Constant & 0.00 & $* * *$ & 0.00 & $* * *$ & 0.00 & $* * *$ & 0.00 & $* * *$ \\
\hline Age & 7.54 & $* * *$ & 9.71 & $* * *$ & 7.54 & $* * *$ & 9.71 & $* * *$ \\
\hline Age squared & 0.96 & $* * *$ & 0.96 & $* * *$ & 0.96 & $* * *$ & 0.96 & $* * *$ \\
\hline \multicolumn{9}{|l|}{ Cohorts (Ref. born 1960-1964) } \\
\hline born 1965-1969 & 0.92 & $* * *$ & 0.85 & $* * *$ & 0.94 & $* * *$ & 0.87 & $* * *$ \\
\hline born 1970-1974 & 0.61 & $* * *$ & 0.47 & $* * *$ & 0.64 & $* * *$ & 0.49 & $* * *$ \\
\hline born 1975-1979 & 0.48 & $* * *$ & 0.35 & $* * *$ & 0.54 & $* * *$ & 0.40 & $* * *$ \\
\hline born 1980-1990 & 0.69 & $* *$ & 0.60 & $*$ & 0.76 & & 0.66 & \\
\hline \multicolumn{9}{|c|}{ Women's education (Ref. less than primary) } \\
\hline primary education & 0.76 & $* * *$ & 0.58 & $* * *$ & 0.76 & $* * *$ & 0.58 & $* * *$ \\
\hline secondary education & 0.57 & $* * *$ & 0.34 & $* * *$ & 0.57 & $* * *$ & 0.33 & $* * *$ \\
\hline college education & 0.48 & $* * *$ & 0.23 & $* * *$ & 0.48 & $* * *$ & 0.23 & $* * *$ \\
\hline \multicolumn{9}{|c|}{ Migration status (Ref. not migrated) } \\
\hline \multicolumn{9}{|l|}{ after migration (first generation } \\
\hline migrants) & 0.11 & $* * *$ & 1.69 & $*$ & 0.17 & $* * *$ & 2.98 & $* * *$ \\
\hline 1.5 generation migrants & 1.06 & & 4.09 & $* *$ & 0.96 & & 2.53 & \\
\hline Age* year of migration & 0.98 & & 0.91 & $* * *$ & 0.99 & & 0.91 & $* * *$ \\
\hline \multicolumn{9}{|c|}{ Age*after migration (first generation } \\
\hline migrants) & 1.07 & $* * *$ & 0.99 & & 1.06 & $* * *$ & 0.98 & * \\
\hline Age*1.5 generation migrants & 0.97 & & 0.92 & $* * *$ & 0.97 & & 0.92 & $* * *$ \\
\hline \multicolumn{5}{|c|}{ Born $1965-1969 *$ year of migration } & 1.47 & $* * *$ & 1.48 & $* * *$ \\
\hline \multicolumn{5}{|c|}{ Born 1965-1969* after migration (first generation migrants) } & 0.82 & $* * *$ & 0.81 & $* * *$ \\
\hline \multicolumn{5}{|c|}{ Born 1965-1969*1.5 generation migrants } & 1.06 & & 1.20 & \\
\hline \multicolumn{5}{|c|}{ Born 1970-1974* year of migration } & 1.16 & & 1.16 & \\
\hline \multicolumn{5}{|c|}{ Born 1970-1974*after migration (first generation migrants) } & 0.73 & $* * *$ & 0.69 & $* * *$ \\
\hline \multicolumn{5}{|c|}{ Born 1970-1974*1.5 generation migrants } & 1.09 & & 1.51 & $*$ \\
\hline \multicolumn{5}{|c|}{ Born 1975-1990* year of migration } & 1.27 & & 1.23 & \\
\hline \multicolumn{5}{|c|}{ Born 1975-1990* after migration (first generation migrants) } & 0.42 & $* * *$ & 0.35 & $* * *$ \\
\hline \multicolumn{5}{|c|}{ Born $1975-1990 * 1.5$ generation migrants } & 1.04 & & 1.68 & \\
\hline
\end{tabular}




\begin{tabular}{|c|c|c|c|c|c|c|c|c|}
\hline \multirow{2}{*}{ Equation 2 - Second Birth } & \multicolumn{2}{|c|}{$\begin{array}{c}\text { Model } 1 \\
\text { Odds Ratio }\end{array}$} & \multicolumn{2}{|c|}{$\begin{array}{c}\text { Model } 2 \\
\text { Odds Ratio }\end{array}$} & \multicolumn{2}{|c|}{$\begin{array}{c}\text { Model } 3 \\
\text { Odds Ratio }\end{array}$} & \multicolumn{2}{|c|}{$\begin{array}{c}\text { Model } 4 \\
\text { Odds Ratio } \\
\end{array}$} \\
\hline & & & & & & & & \\
\hline Constant & 13.72 & $* * *$ & 0.02 & $* * *$ & 15.60 & $* * *$ & 0.03 & $* * *$ \\
\hline Age & 0.79 & $* * *$ & 1.10 & $*$ & 0.78 & $* * *$ & 1.08 & \\
\hline Age squared & 1.00 & $* * *$ & 1.00 & & 1.00 & $* * *$ & 1.00 & \\
\hline Duration since last birth & 1.23 & $* * *$ & 1.17 & $* * *$ & 1.23 & $* * *$ & 1.18 & $* * *$ \\
\hline Duration since last birth squared & 0.97 & $* * *$ & 0.97 & $* * *$ & 0.97 & $* * *$ & 0.97 & $* * *$ \\
\hline \multicolumn{9}{|l|}{ Cohorts (Ref. born 1960-1964) } \\
\hline born 1965-1969 & 0.74 & $* * *$ & 0.65 & $* * *$ & 0.69 & $* * *$ & 0.59 & $* * *$ \\
\hline born 1970-1974 & 0.42 & $* * *$ & 0.27 & $* * *$ & 0.41 & $* * *$ & 0.26 & $* * *$ \\
\hline born 1975-1979 & 0.23 & $* * *$ & 0.15 & $* * *$ & 0.26 & $* * *$ & 0.14 & $* * *$ \\
\hline born $1980-1990$ & 0.07 & $* * *$ & 0.04 & $* * *$ & 0.09 & $* * *$ & 0.05 & $* * *$ \\
\hline \multicolumn{9}{|c|}{ Women's education (Ref. less than primary) } \\
\hline primary education & 0.69 & $* * *$ & 0.54 & $* * *$ & 0.69 & $* * *$ & 0.54 & $* * *$ \\
\hline secondary education & 0.41 & $* * *$ & 0.24 & $* * *$ & 0.41 & $* * *$ & 0.24 & $* * *$ \\
\hline college education & 0.11 & $* * *$ & 0.04 & $* * *$ & 0.26 & $* * *$ & 0.04 & $* * *$ \\
\hline \multicolumn{9}{|l|}{ Migration status (Ref. not migrated) } \\
\hline year of migration & 1.15 & & 3.51 & $* * *$ & 0.89 & & 2.57 & $* *$ \\
\hline \multicolumn{9}{|l|}{ after migration (first generation } \\
\hline migrants) & 6.02 & $* * *$ & 20.54 & $* * *$ & 5.72 & $* * *$ & 19.37 & $* * *$ \\
\hline 1.5 generation migrants & 3.47 & $* * *$ & 4.40 & $* * *$ & 3.37 & $* *$ & 3.13 & $*$ \\
\hline First child female & 1.56 & $* * *$ & 1.67 & $* * *$ & 1.56 & $* * *$ & 1.67 & $* * *$ \\
\hline \multicolumn{9}{|l|}{ First child female * after migration } \\
\hline (first generation migrant) & 0.72 & & 0.69 & & 0.72 & & 0.69 & \\
\hline \multicolumn{9}{|l|}{ First child female * US, 1.5} \\
\hline generation migrant & 0.62 & & 0.57 & & 0.62 & & 0.58 & \\
\hline $\begin{array}{l}\text { Duration since last birth*year of } \\
\text { migration }\end{array}$ & 1.15 & & 1.09 & & 1.15 & & 1.09 & \\
\hline \multicolumn{9}{|l|}{ Duration since last birth*after } \\
\hline migration (first generation migrants) & 1.07 & & 1.12 & $* *$ & 1.06 & & 1.11 & $* *$ \\
\hline \multicolumn{9}{|l|}{ Duration since last birth*1.5 } \\
\hline generation migrants & 2.02 & $* * *$ & 2.32 & $* * *$ & 2.00 & $* * *$ & 2.28 & $* * *$ \\
\hline \multicolumn{9}{|l|}{ Duration since last birth squared*year } \\
\hline of migration & 1.00 & & 1.00 & & 1.00 & & 1.00 & \\
\hline \multicolumn{9}{|l|}{ Duration since last birth } \\
\hline \multicolumn{9}{|l|}{ squared ${ }^{*}$ after migration (first } \\
\hline generation migrants) & 1.00 & & 1.00 & & 1.00 & & 1.00 & \\
\hline \multicolumn{9}{|l|}{ Duration since last birth squared $* 1.5$} \\
\hline generation migrants & 0.92 & $* * *$ & 0.91 & $* * *$ & 0.92 & $* * *$ & 0.91 & $* * *$ \\
\hline Born 1965-1969 * year of migration & & & & & 1.59 & $*$ & 1.84 & $* *$ \\
\hline Born 1965-1969* after migration (fir & eneratio & $n$ mig & & & 1.16 & $*$ & 1.22 & $* *$ \\
\hline Born $1965-1969 * 1.5$ generation mig & & & & & 1.10 & & 1.57 & \\
\hline Born 1970-1974 * year of migration & & & & & 1.34 & & 1.49 & \\
\hline
\end{tabular}


Born 1970-1974*after migration (first generation migrants)

1.00

1.13

Born 1970-1974*1.5 generation migrants

1.06

1.44

Born 1975-1990* year of migration

4.52

6.86

Born 1975-1990* after migration (first generation migrants)

0.86

1.14

Born 1975-1990*1.5 generation migrants

0.70 


\begin{tabular}{|c|c|c|c|c|c|c|c|c|}
\hline \multirow{2}{*}{ Equation 3 - Third Birth } & \multicolumn{2}{|c|}{$\begin{array}{l}\text { Model } 1 \\
\text { Odds Ratio }\end{array}$} & \multicolumn{2}{|c|}{$\begin{array}{l}\text { Model } 2 \\
\text { Odds Ratio }\end{array}$} & \multicolumn{2}{|c|}{$\begin{array}{l}\text { Model } 3 \\
\text { Odds Ratio }\end{array}$} & \multicolumn{2}{|c|}{$\begin{array}{l}\text { Model } 4 \\
\text { Odds Ratio }\end{array}$} \\
\hline & \multirow{2}{*}{\multicolumn{2}{|c|}{0.88}} & \multirow[b]{2}{*}{0.00} & \multirow[b]{2}{*}{$* * *$} & \multirow{2}{*}{\multicolumn{2}{|c|}{1.13}} & \multirow[b]{2}{*}{0.00} & \multirow[b]{2}{*}{$* * *$} \\
\hline Constant & & & & & & & & \\
\hline Age & 0.99 & & 1.34 & $* *$ & 0.97 & & 1.27 & $*$ \\
\hline Age squared & 1.00 & $*$ & 0.99 & $* * *$ & 1.00 & & 0.99 & $* * *$ \\
\hline Duration since last birth & 1.34 & $* *$ & 1.28 & $* *$ & 1.35 & $* * *$ & 1.29 & $* *$ \\
\hline Duration since last birth squared & 0.94 & $* * *$ & 0.94 & $* * *$ & 0.94 & $* * *$ & 0.94 & $* * *$ \\
\hline \multicolumn{9}{|l|}{ Cohorts (Ref. born 1960-1964) } \\
\hline born 1965-1969 & 0.52 & $* * *$ & 0.40 & $* * *$ & 0.49 & $* * *$ & 0.36 & $* * *$ \\
\hline born $1970-1974$ & 0.34 & $* * *$ & 0.17 & $* * *$ & 0.34 & $* * *$ & 0.15 & $* * *$ \\
\hline born $1975-1990$ & 0.26 & $* * *$ & 0.11 & $* * *$ & 0.26 & $* * *$ & 0.10 & $* * *$ \\
\hline \multicolumn{9}{|c|}{ Women's education (Ref. less than primary) } \\
\hline primary education & 0.76 & $* *$ & 0.54 & $* * *$ & 0.77 & $* *$ & 0.54 & $* * *$ \\
\hline secondary education & 0.55 & $* * *$ & 0.29 & $* * *$ & 0.56 & $* * *$ & 0.29 & $* * *$ \\
\hline college education & 0.21 & $* * *$ & 0.08 & $* * *$ & 0.21 & $* * *$ & 0.08 & $* * *$ \\
\hline \multicolumn{9}{|c|}{$\begin{array}{l}\text { Migration status (Ref. not migrated and year of migration) } \\
\text { after migration (first generation }\end{array}$} \\
\hline migrants) & 1.84 & $* *$ & 9.30 & $* * *$ & 1.70 & & 8.29 & $* * *$ \\
\hline 1.5 generation migrants & 3.10 & $* *$ & 7.07 & $* * *$ & 4.63 & $* * *$ & 8.23 & $* * *$ \\
\hline First two children female & 3.50 & $* * *$ & 4.37 & $* * *$ & 3.51 & $* * *$ & 4.39 & $* * *$ \\
\hline \multicolumn{9}{|l|}{ First two children female * after } \\
\hline migration (first generation migrant) & \multicolumn{2}{|l|}{0.67} & \multicolumn{2}{|l|}{0.59} & \multicolumn{2}{|l|}{0.66} & \multicolumn{2}{|l|}{0.59} \\
\hline \multicolumn{9}{|l|}{ First two children female *US, 1.5} \\
\hline generation migrant & \multicolumn{2}{|l|}{0.40} & \multicolumn{2}{|l|}{0.32} & \multicolumn{2}{|l|}{0.40} & \multicolumn{2}{|l|}{0.33} \\
\hline \multicolumn{9}{|l|}{ Duration since last birth*after } \\
\hline migration (first generation migrants) & \multicolumn{2}{|l|}{0.99} & \multicolumn{2}{|l|}{1.01} & 0.99 & & 1.00 & \\
\hline Duration since last birth $* 1.5$ & & & & & & & & \\
\hline generation migrants & 0.96 & & 0.97 & & 0.97 & & 0.95 & \\
\hline Duration since last birth squared $*$ afte & & & & & & & & \\
\hline migration (first generation migrants) & 1.03 & & 1.02 & & 1.03 & & 1.03 & \\
\hline Duration since last birth squared $* 1.5$ & & & & & & & & \\
\hline generation migrants & 1.03 & & 1.03 & & 1.03 & & 1.04 & \\
\hline Born 1965-1969* after migration (fir & eneratior & migr & & & 1.17 & & 1.34 & \\
\hline Born 1965-1969* 1.5 generation mig & & & & & 0.65 & & 0.92 & \\
\hline Born 1970-1990* after migration (fir & eneratior & migr & & & 1.23 & & 1.58 & \\
\hline Born $1970-1990 * 1.5$ generation mig & & & & & 0.50 & & 0.71 & \\
\hline
\end{tabular}




\begin{tabular}{|c|c|c|c|c|c|c|c|c|}
\hline & \multicolumn{2}{|c|}{$\begin{array}{l}\text { Model } 1 \\
\text { Odds Ratio }\end{array}$} & \multicolumn{2}{|c|}{$\begin{array}{l}\text { Model } 2 \\
\text { Odds Ratio }\end{array}$} & \multicolumn{2}{|c|}{$\begin{array}{l}\text { Model } 3 \\
\text { Odds Ratio }\end{array}$} & \multicolumn{2}{|c|}{$\begin{array}{l}\text { Model } 4 \\
\text { Odds Ratio }\end{array}$} \\
\hline \multicolumn{9}{|l|}{ Equation 4 - Migration } \\
\hline Constant & 0.00 & $* * *$ & 0.00 & $* * *$ & 0.00 & $* * *$ & 0.00 & $* * *$ \\
\hline Age & 1.87 & $* * *$ & 3.25 & $* * *$ & 1.87 & $* * *$ & 3.23 & $* * *$ \\
\hline Age squared & 0.99 & $* * *$ & 0.98 & $* * *$ & 0.99 & $* * *$ & 0.98 & $* * *$ \\
\hline \multicolumn{9}{|l|}{ Cohorts (Ref. born 1960-1964) } \\
\hline born 1965-1969 & 0.97 & & 1.46 & $* * *$ & 0.97 & & 1.49 & $* * *$ \\
\hline born 1970-1974 & 1.24 & $* * *$ & 3.01 & $* * *$ & 1.24 & $* * *$ & 3.16 & $* * *$ \\
\hline born 1975-1979 & 1.80 & $* * *$ & 6.28 & $* * *$ & 1.80 & $* * *$ & 6.66 & $* * *$ \\
\hline born 1980-1990 & 2.74 & $* * *$ & 14.49 & $* * *$ & 2.74 & $* * *$ & 15.82 & $* * *$ \\
\hline \multicolumn{9}{|c|}{ Women's education (Ref. less than primary) } \\
\hline primary education & 0.86 & $*$ & 1.21 & & 0.86 & $*$ & 1.25 & \\
\hline secondary education & 0.88 & $*$ & 1.03 & & 0.88 & $*$ & 1.06 & \\
\hline college education & 1.12 & & 1.28 & & 1.12 & & 1.32 & \\
\hline GDP growth rate, China & 0.03 & $* * *$ & 0.02 & $* * *$ & 0.03 & $* * *$ & 0.02 & $* * *$ \\
\hline Urbanization rate, China & 4.97 & $* * *$ & 2.59 & & 4.98 & $* * *$ & 2.46 & \\
\hline Unemployment rate, US & 1.03 & & 1.03 & & 1.03 & & 1.04 & \\
\hline \multicolumn{9}{|c|}{ US migration policy towards Chinese (Ref. Chinese immigration act 1923) } \\
\hline Illegal Immigration Reform Act 1996 & 0.83 & $* * *$ & 0.87 & $*$ & 0.83 & $* * *$ & 0.87 & $*$ \\
\hline \multicolumn{9}{|c|}{ Chinese emigration policy (Ref. before open economy) } \\
\hline open up economy 1978 & 1.96 & $* *$ & 1.84 & $*$ & 1.96 & $* *$ & 1.88 & $*$ \\
\hline first set of migration law 1985 & 2.16 & $* *$ & 2.00 & $*$ & 2.16 & $* *$ & 2.05 & $*$ \\
\hline \multicolumn{9}{|l|}{ official document on tightening } \\
\hline controls 1992 & 2.17 & $* *$ & 1.95 & $*$ & 2.17 & $* *$ & 2.00 & $*$ \\
\hline \multicolumn{9}{|l|}{ law amendment on penalties for } \\
\hline smuggling & 2.37 & $* *$ & 2.42 & $* *$ & 2.37 & $* *$ & 2.48 & $* *$ \\
\hline passport policy normalization & 1.00 & & 1.02 & & 1.00 & & 1.04 & \\
\hline \multicolumn{9}{|l|}{ Enhancement of household contract } \\
\hline responsibility policy 1984 & 1.07 & & 1.00 & & 1.07 & & 1.01 & \\
\hline \multicolumn{9}{|c|}{ Standard deviations and correlation between heterogeneity components (error terms) } \\
\hline \multicolumn{9}{|l|}{ Standard deviation of the heterogeneity } \\
\hline component, fertility (Sigma $\varepsilon$ ) & & & 1.26 & $* * *$ & & & 1.25 & $* * *$ \\
\hline \multicolumn{9}{|l|}{ Standard deviation of the heterogeneity } \\
\hline component, migration (Sigma $\lambda$ ) & & & 3.00 & & & & 3.00 & \\
\hline \multicolumn{9}{|l|}{ Correlation between the heterogeneity } \\
\hline \multicolumn{3}{|c|}{ components for migration and fertility (Rho) } & -0.66 & $* * *$ & & & -0.66 & $* * *$ \\
\hline Log-likelihood & & 9310 & & 7792 & & 9270 & & 7747 \\
\hline
\end{tabular}

Note: ${ }^{*} p<0.1 ;{ }^{* *} p<0.05 ;{ }^{* * *} p<0.01$. The dependent variables of Equations 1 to 4 are the likelihood of the first, second and third birth, and migration. Model 2 and Model 4 take into account unobserved factors while Model 1 and 3 do not. 
Table 2. Simultaneous Equation Models: Duration since Migration (Model 5), Policy and Migration status (Model 6) and Policy and Migration Status for women with at most primary school education (Model 7) and women with at least secondary education (Model 8)

\begin{tabular}{|c|c|c|c|c|c|c|c|}
\hline & $\begin{array}{c}\text { Model } 5 \\
\text { Odds Ratio }\end{array}$ & \multicolumn{2}{|c|}{$\begin{array}{c}\text { Model } 6 \\
\text { Odds Ratio }\end{array}$} & \multicolumn{2}{|c|}{$\begin{array}{c}\text { Model } 7 \\
\text { Odds Ratio }\end{array}$} & \multicolumn{2}{|c|}{$\begin{array}{c}\text { Model } 8 \\
\text { Odds Ratio }\end{array}$} \\
\hline \multicolumn{8}{|l|}{ First Birth } \\
\hline \multicolumn{8}{|c|}{ Duration since migration (Ref. non migrant) } \\
\hline year of migration & $0.62 * * *$ & & & & & & \\
\hline 1 to 3 years after migration & $1.16 * * *$ & & & & & & \\
\hline more than 3 years after migration & $1.26 * * *$ & & & & & & \\
\hline \multicolumn{8}{|c|}{$\begin{array}{l}\text { Policy and migration status (Ref. only one child allowed, living in China) } \\
\text { more than one child allowed, living in }\end{array}$} \\
\hline China & & 1.14 & $* * *$ & 1.06 & & 1.05 & $*$ \\
\hline year of migration & & 0.69 & $* * *$ & 1.68 & $* * *$ & 0.65 & $* * *$ \\
\hline \multicolumn{8}{|l|}{ after migration (first generation } \\
\hline migrants) & & 1.44 & $* * *$ & 2.59 & $* * *$ & 1.33 & $* * *$ \\
\hline 1.5 generation migrants & & 0.47 & $* * *$ & 0.60 & $* *$ & 0.47 & $* * *$ \\
\hline
\end{tabular}

\section{Second Birth}

Duration since migration (Ref. non migrant)

year of migration

$5.40 * * *$

1 to 3 years after migration

$14.20 * * *$

more than 3 years after migration

$31.90 * * *$

Policy and migration status (Ref. fewer than two children allowed, living in China) at least two children allowed, living in

\begin{tabular}{|c|c|c|c|c|c|c|c|c|}
\hline China & & & 1.07 & & 1.06 & & 1.00 & \\
\hline year of migration & & & 5.48 & $* * *$ & 2.48 & $* * *$ & 4.81 & $* * *$ \\
\hline \multicolumn{9}{|c|}{ after migration (first generation } \\
\hline migrants) & & & 32.02 & $* * *$ & 7.72 & $* * *$ & 35.90 & $* * *$ \\
\hline 1.5 generation migrants & & & 17.5 & $* * *$ & 2.41 & $* *$ & 19.63 & $* * *$ \\
\hline First child female & 1.42 & $* * *$ & 1.15 & $* * *$ & 1.67 & $* * *$ & 1.73 & $* * *$ \\
\hline \multicolumn{9}{|c|}{ First child female * living in China, } \\
\hline first generation & & & 0.99 & $* * *$ & 0.68 & $* * *$ & 0.33 & $* * *$ \\
\hline \multicolumn{9}{|c|}{ First child female * living in China, } \\
\hline 1.5 generation & & & 0.82 & $* * *$ & 0.99 & $* * *$ & 0.99 & $* * *$ \\
\hline
\end{tabular}

\section{Third Birth}

Duration since migration (Ref. non migrant) year of migration 1.18

1 to 3 years after migration

more than 3 years after migration

$11.72 * * *$

Policy and migration status (Ref. fewer than three children allowed, living in China) year of migration 1.26 $2.26 * *$ after migration (first generation migrants) 
1.5 generation migrants

First and second births females

3.52

9.47

$* * *$

1.65

$9.96 * * *$

First two children female * living in

the US, first generation

$0.57 * * *$

First two children female * living in

0.32

the US, 1.5 generation

Standard deviation and correlation between heterogeneity components (error terms)

Standard deviation of the

heterogeneity component, fertility

(Sigma \&)

$1.28 * * *$

$1.23 * * *$

$1.31 * * *$

$1.13 * * *$

Standard deviation of the

heterogeneity component, migration

(Sigma $\lambda$ )

3.00

3.00

3.00

3.00

Correlation between the

heterogeneity components for

migration and fertility (Rho)

Log-likelihood

$-0.64$

$-107861$
$-0.66$

$-107825$

$-0.69$

$* * * \quad-0.64$

$-40461$

Note: The dependent variables of first three panels are the likelihood of the first, second and third birth. Age, age squared, duration since last birth and duration since last birth squared (for the second and third births), birth cohort, education level are included in all models. 


\section{Appendix}

Table A1 Provinces and year of family policy changes allowing women to bear a second child if they fulfill the stated conditions

\begin{tabular}{|c|c|c|}
\hline $\begin{array}{l}\text { Province } \\
\text { Name }\end{array}$ & $\begin{array}{l}\text { If both couple members are only } \\
\text { child they become allowed to give } \\
\text { birth to a second child }\end{array}$ & $\begin{array}{l}\text { If the couple has a rural hukou* } \\
\text { and the first child is a girl they } \\
\text { become allowed to give birth to } \\
\text { a second child }\end{array}$ \\
\hline AnHui & Since 1988 , both rural and urban hukou & since 2002 \\
\hline BeiJing & since 1991 , both rural and urban hukou & not Applicable \\
\hline \multirow[t]{2}{*}{ FuJian } & since 1988 , rural hukou & since 2000 \\
\hline & since 2002, urban hukou & \\
\hline GanSu & since 2002 , both rural and urban hukou & since 1997 \\
\hline GuangDong & since 1986 , both rural and urban hukou & since 1986 \\
\hline GuangXi & since 1988 , both rural and urban hukou & since 1988 \\
\hline GuiZhou & since 1998 , both rural and urban hukou & since 1998 \\
\hline HaiNan & since 1989 , both rural and urban hukou & since 1989 \\
\hline HeBei & since 1989 , both rural and urban hukou & Since 1994 \\
\hline HeiLongJiang & since 1989 , both rural and urban hukou & since 1989 \\
\hline HeNan & since 2011 , both rural and urban hukou & since 1990 \\
\hline HuBei & since 2002, urban hukou & since 1988 \\
\hline HuNan & since 1989 , both rural and urban hukou & since 1989 \\
\hline Inner & since 2002 , rural hukou & since 1990 \\
\hline \multicolumn{3}{|l|}{ Mongolia } \\
\hline JiangSu & since 1990 , both rural and urban hukou & since 1990 \\
\hline JiangXi & Since 1990 , both rural and urban hukou & since 1990 \\
\hline JiLin & since 1993 , both rural and urban hukou & since 2002 \\
\hline LiaoNing & since 1988 , both rural and urban hukou & since 1988 \\
\hline NingXia & since 1980 , both rural and urban hukou & since 1980 \\
\hline
\end{tabular}




\begin{tabular}{|c|c|c|}
\hline QingHai & since 1980 , rural hukou & since 1980 \\
\hline & since 1986 , urban hukou & \\
\hline ShaanXi & since 1986 , both rural and urban hukou & since 1997 \\
\hline ShanDong & since 1988 , both rural and urban hukou & since 1988 \\
\hline ShangHai & since 1990 , both rural and urban hukou & not Applicable \\
\hline ShanXi & since 1999 , both rural and urban hukou & since 1999 \\
\hline SiChuan & since 1987 , both rural and urban hukou & not Applicable \\
\hline TianJin & since 1988 , both rural and urban hukou & since 1994 \\
\hline \multirow[t]{2}{*}{ Tibet } & since 1980 , rural hukou & since 1980 \\
\hline & since 1992, urban hukou & \\
\hline \multirow[t]{2}{*}{ XinJiang } & since 1980 , rural hukou & since 1980 \\
\hline & since 2002, urban hukou & \\
\hline \multirow[t]{2}{*}{ YunNan } & since 1980 , rural hukou & since 1980 \\
\hline & since 1990 , urban hukou & \\
\hline ZheJiang & since 1985 , both rural and urban hukou & since 2002 \\
\hline
\end{tabular}

Note: Hukou refers to the municipal registration. "Both rural and urban hukou" means the condition under which a second birth is allowed applies to those with both rural and urban hukou in a certain province during a specific time period, while "rural hukou" means that the condition only applies to rural dwellers and "urban hukou" only applies to urban citizens in the province and time period indicated. This table covers the policies since 1980, when the one child policy was introduced, so "since 1980" means that a second birth was always allowed since the beginning of the policy for people meeting certain requirements, for example, if both couple members were only children or if the couple had a rural hukou and the first child was a girl. 


\section{A2. The Matching Technique}

Information on the treatment and control groups (i.e., migrants and non-migrants) are from different data sources and, thus, involve different sampling strategies. The two countries where data on migrants and non-migrants were obtained (China and the United States), differ in various aspects, including age structure, education level, and birth-cohort size according to our data. The assignments of treatment in this case, migrants or not - are not random, but selectivity on, for example, age, education level, and birth-cohort size differs in the treatment and control group. The goal of propensity score matching is to create a dataset similar to what would result from a randomized experiment (Ho et al., 2011). To improve comparability, exact matching is preferred when non-trivial differences exist between the treatment and control group such that a substantial portion of observations in either group would be dropped because of noncomparativity (see Riosmena, Kuhn, \& Jochem, 2017). For this reason, we applied exact matching, given the limited number of variables on which matching was implemented. In this procedure, we obtained pairs of migrant and non-migrant women, extracted from the US and Chinese samples, respectively, who shared the same birth cohort, age, and educational level but differed in migration experience.

After applying weights using the R package "Matchit," we had each matched control (non-migrant) unit with a weight proportional to the number of treatment units (migrants) to which it was matched. We retained all treatment units (migrants) with a weight of 1 and weight controls to be included in the final dataset. In this manner, the sum of control weights was equal to the number of uniquely matched treatment units (Ho et al., 2011). After propensity score matching was applied, we obtained a weight similar to a population weight. After applying weights, the age, cohort, and educational structures of 
the non-migrant sample from the Chinese data and migrant sample from the US data are the same. Moreover, the modeling choice would be much less consequential after matching (Ho et al., 2011).

The discrete-time event history model was then estimated, using a weighted likelihood estimator. There are $n$ populations, in our case, two populations, including non-migrants sampled in China and Chinese migrants sampled in the United States. Both migrants and non-migrants were randomly and independently sampled. If $\theta_{i} \rightarrow \int \ln \left\{f_{i}\left(y \mid \theta_{i}\right)\right\} f_{i}(y) d \mu(y)$ is continuously differentiable on $\theta$, then, $\theta_{i}$ maximizes $\sum_{j=1}^{n} w_{i j} \int \ln \left\{f_{i}\left(y \mid \theta_{i}\right)\right\} f_{i}(y) d \mu(y)$ for certain constant weights $w_{i j}$ (Hu \& Zidek, 2019). In this manner, the weights enter into the likelihood estimation based on the weighted likelihood method. 
Figure A3. Simulated conditional annual probabilities of first, second and third birth for hypothetical migrant and non-migrant women with less than primary education and with a university education, who migrated at age 30 . Migration takes place 3 years after first birth (or three years after second birth).

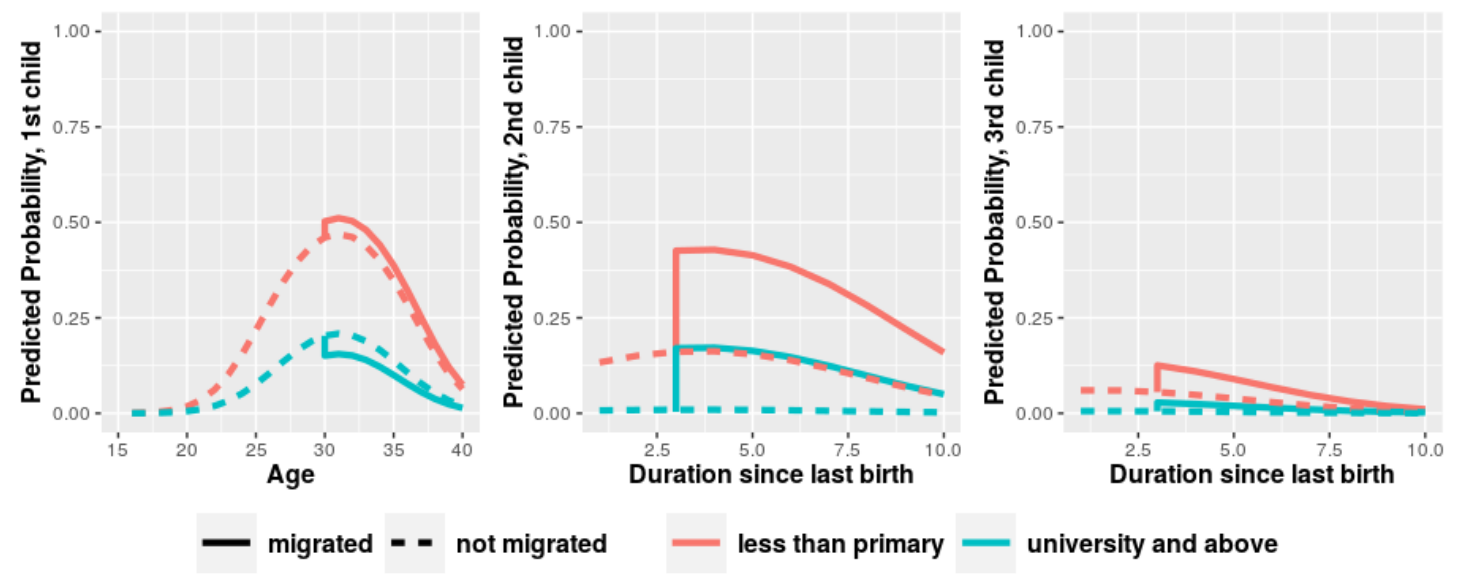

Note: Model specification as Model 2. 